Article

\title{
Evaluation of Antibiotic Resistance of Salmonella Serotypes and Whole-Genome Sequencing of Multiresistant Strains Isolated from Food Products in Russia
}

\author{
Andrey L. Rakitin ${ }^{1} \oplus$, Yulia K. Yushina ${ }^{2, *}{ }^{\oplus}$, Elena V. Zaiko ${ }^{2} \oplus$, Dagmara S. Bataeva ${ }^{2}$, Oksana A. Kuznetsova ${ }^{2}$, \\ Anastasia A. Semenova ${ }^{2}{ }^{\circ}$, Svetlana A. Ermolaeva ${ }^{3,4}{ }^{\circledR}$, Aleksey V. Beletskiy ${ }^{1}$, Tat'yana V. Kolganova ${ }^{1}{ }^{1}$, \\ Andrey V. Mardanov ${ }^{1}{ }^{1}$, Sergei O. Shapovalov ${ }^{5}$ and Timofey E. Tkachik ${ }^{5}$ \\ 1 Research Center of Biotechnology, Institute of Bioengineering, Russian Academy of Sciences, \\ 119071 Moscow, Russia; rakitin@biengi.ac.ru (A.L.R.); mortu@yandex.ru (A.V.B.); \\ moldiag@biengi.ac.ru (T.V.K.); mardanov@biengi.ac.ru (A.V.M.) \\ 2 V.M. Gorbatov Federal Research Center for Food Systems of Russian Academy of Sciences, \\ 109316 Moscow, Russia; e.zaiko@fncps.ru (E.V.Z.); d.bataeva@fncps.ru (D.S.B.); \\ o.kuznecova@fncps.ru (O.A.K.); a.semenova@fncps.ru (A.A.S.) \\ 3 Federal Research Center for Virology and Microbiology, Nizhny Novgorod Research Veterinary Institute \\ Branch, 603950 Nizhny Novgorod, Russia; drermolaeva@mail.ru \\ 4 Gamaleya National Research Centre for Epidemiology and Microbiology, 123098 Moscow, Russia \\ 5 Research and Scientific Testing Center "Cherkizovo", 108805 Moscow, Russia; \\ shapovalov73@rambler.ru (S.O.S.); tim.tkachik@gmail.com (T.E.T.) \\ check for \\ * Correspondence: yu.yushina@fncps.ru; Tel.: +7-495-676-60-11
} updates

Citation: Rakitin, A.L.; Yushina, Y.K.; Zaiko, E.V.; Bataeva, D.S.;

Kuznetsova, O.A.; Semenova, A.A.; Ermolaeva, S.A.; Beletskiy, A.V.; Kolganova, T.V.; Mardanov, A.V.; et al. Evaluation of Antibiotic Resistance of Salmonella Serotypes and Whole-Genome Sequencing of Multiresistant Strains Isolated from Food Products in Russia. Antibiotics 2022, 11, 1. https://doi.org/ 10.3390/antibiotics 11010001

Academic Editor:

David Rodríguez-Lázaro

Received: 31 October 2021

Accepted: 17 December 2021

Published: 21 December 2021

Publisher's Note: MDPI stays neutral with regard to jurisdictional claims in published maps and institutional affiliations.

Copyright: (C) 2021 by the authors. Licensee MDPI, Basel, Switzerland. This article is an open access article distributed under the terms and conditions of the Creative Commons Attribution (CC BY) license (https:// creativecommons.org/licenses/by/ $4.0 /)$.
Abstract: Food products may be a source of Salmonella, one of the main causal agents of food poisoning, especially after the emergence of strains resistant to antimicrobial preparations. The present work dealt with investigation of the occurrence of resistance to antimicrobial preparations among S. enterica strains isolated from food. The isolates belonged to 11 serovars, among which Infantis (28\%), Enteritidis (19\%), and Typhimurium (13.4\%) predominated. The isolates were most commonly resistant to trimethoprim/sulfamethoxazole ( $n=19,59.38 \%)$, cefazolin $(n=15,46.86 \%)$, tetracycline $(n=13,40.63 \%)$, and amikacin $(n=9,28.13 \%)$. Most of the strains $(68.75 \%)$ exhibited multiple resistance to commonly used antibiotics. High-throughput sequencing was used to analyse three multidrug-resistant strains (resistant to six or more antibiotics). Two of them (SZL 30 and SZL 31 ) belonged to $S$. Infantis, while one strain belonged to $S$. Typhimurium (SZL 38). Analysis of the genomes of the sequenced strains revealed the genes responsible for antibiotic resistance. In the genomes of strains SZL 30 and SZL 31 the genes of antibiotic resistance were shown to be localized mostly in integrons within plasmids, while most of the antibiotic resistance genes of strain SZL 38 were localized in a chromosomal island (17,949 nt). Genomes of the Salmonella strains SZL 30, SZL 31, and SZL 38 were shown to contain full-size pathogenicity islands: SPI-1, SPI-2, SPI-4, SPI-5, SPI-9, SPI-11, SPI-13, SPI-14, and CS54. Moreover, the genome of strain SZL 38 was also found to contain the full-size pathogenicity islands SPI-3, SPI-6, SPI-12, and SPI-16. The emergence of multidrug-resistant strains of various Salmonella serovars indicates that further research on the transmission pathways for these genetic determinants and monitoring of the distribution of these microorganisms are necessary.

Keywords: Salmonella; foodborne pathogen; serotype; WGS; antimicrobial resistance

\section{Introduction}

Food safety is a key problem worldwide, while the provision of pathogen-free food is an important social problem. Food pathogens are among the major food-related risk factors, affecting over 2 billion people per year [1]. Salmonella strains are among the major causes of foodborne diseases in many regions worldwide [2]. Salmonella is common among wild and domesticated animals, including the animals used by humans for food. While over 
2600 Salmonella serotypes are presently known, almost 99\% of the serotypes associated with diseases of humans and warm-blood animals belong to S. enterica subspecies enterica [3].

In the Russian Federation, salmonellosis remains an important cause for outbursts, being third in the nidus structure of group disease incidence among infections with a faecaloral transmission mechanism. In 2020, 20 outbreaks of salmonellosis were recorded with a total of 422 people affected [4]. In cases of this disease, the strategy involves determination of the medically important serovars and of their sources in order to undertake relevant measures to limit their propagation [5].

In humans, Salmonella-infected foods usually cause an enteric disease which is cured by itself and, as a rule, does not require serious medical interference [6]. However, a severe form of this disease, occurring in 2-3\% of all cases, may result in sepsis and other system disorders, especially in children, senior citizens, and people with impaired immunity. In these situations, antibiotic treatment may be an important life-saving measure [7,8]. Apart from their pathogenic potential, Salmonella strains may develop resistance to one or several antibiotics, which may hinder medical treatment. Unjustified application of antibiotics in livestock farming may favour the emergence of strains with multidrug resistance; this resistance may be transmitted by mobile genetic elements.

Reports on Salmonella resistance to antimicrobial preparations, including cases of multiple resistance, with three or more preparations inefficient against a certain strain, have become more frequent with time [9-11].

Full-genome sequencing is presently recommended for characterization of microorganisms, since it provides extensive information, including serovar distribution, profiles of the virulence and antibiotic resistance genes, and the presence of plasmids. It also makes possible multilocus typing using the sequences obtained [12].

The NCBI GenBank database presently contains over 12,500 full-size sequences of the species S. enterica. Numerous works on Salmonella genomes deal with the detection of genetic loci related to pathogenesis: antibiotic resistance genes, which are often located in integrons or transposons; Salmonella pathogenicity islands (SPI); and bacteriophages [13-16].

Microbial resistance to antibiotics may be caused by several mechanisms [17-19]: (1) inactivation of an antibiotic by its enzymatic modification via phosphorylation, adenylation, or acetylation; (2) modification of the antibiotic target site; (3) release of antibiotic from the cell by various transporters; and (4) decreased membrane permeability.

The aim of this work was to study the antimicrobial resistance of various serotypes of Salmonella derived from food. Genome-wide sequencing of multiresistant strains was carried out in order to study the determinants of antibiotic resistance, pathogenicity islands, and phages localized in the genomes of these strains.

\section{Results}

\subsection{Prevalence of Salmonella spp. in Food Products}

Of the 474 samples, $32(6.8 \%)$ were positive for Salmonella spp.: 12 poultry samples $(10.7 \%), 3$ pork samples $(3.3 \%), 7$ beef samples $(6.8 \%)$, and 10 minced meat samples $(6 \%)$ (Table 1).

Table 1. Prevalence of Salmonella isolated from food products.

\begin{tabular}{ccc}
\hline Sample Type & Number of Samples Analysed & Number of Positive Samples (\%) \\
\hline Poultry & 112 & $12(10.7)$ \\
\hline Pork & 91 & $3(3.3)$ \\
\hline Beef & 103 & $7(6.8)$ \\
\hline Minced meat & 168 & $10(6)$ \\
\hline Total & 474 & $32(6.8)$ \\
\hline
\end{tabular}




\subsection{Serological Identification of Salmonella}

The studied isolates belonged to 11 serovars. The most common serovars were Infantis $(28.13 \%, n=9)$, then Enteritidis $(18.75 \%, n=6)$, Typhimurium $(12.50 \%, n=4)$, Reading $(9.38 \%, n=3)$, Derby, Rissen, and Kentucky $(6.25 \%, n=2)$, and Give, Idikan, Genovar, and Indiana $(3.13 \%, n=1)$ (Figure 1$)$.

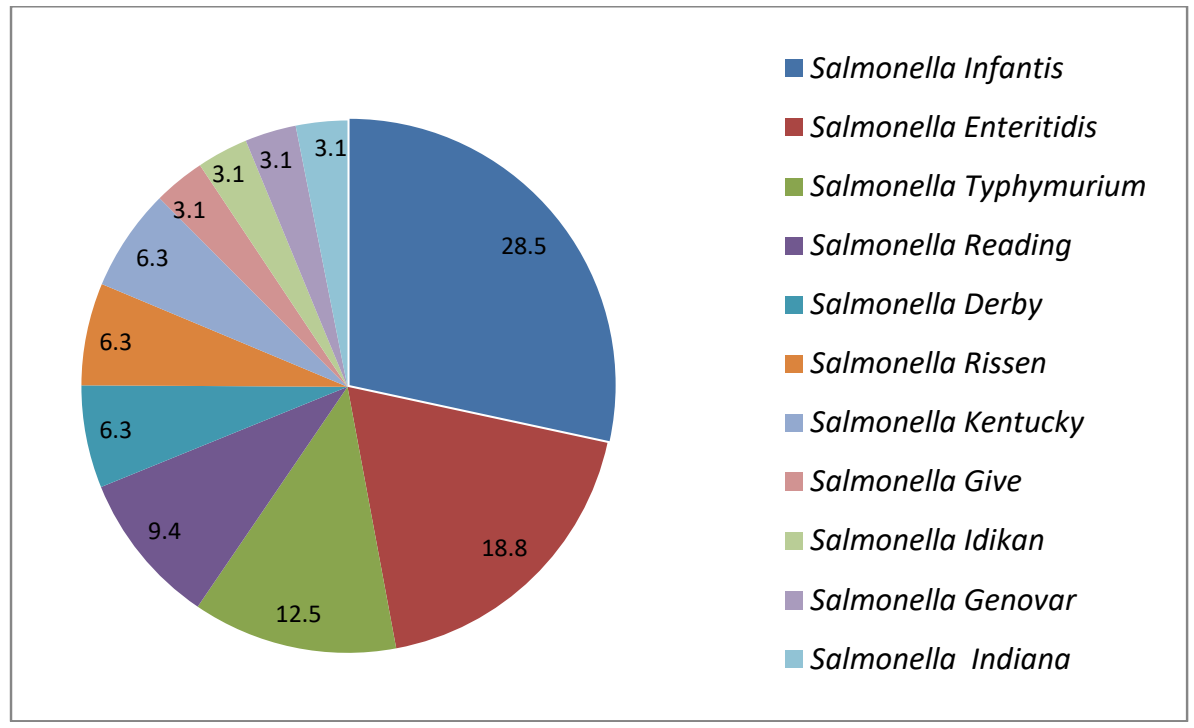

(A)

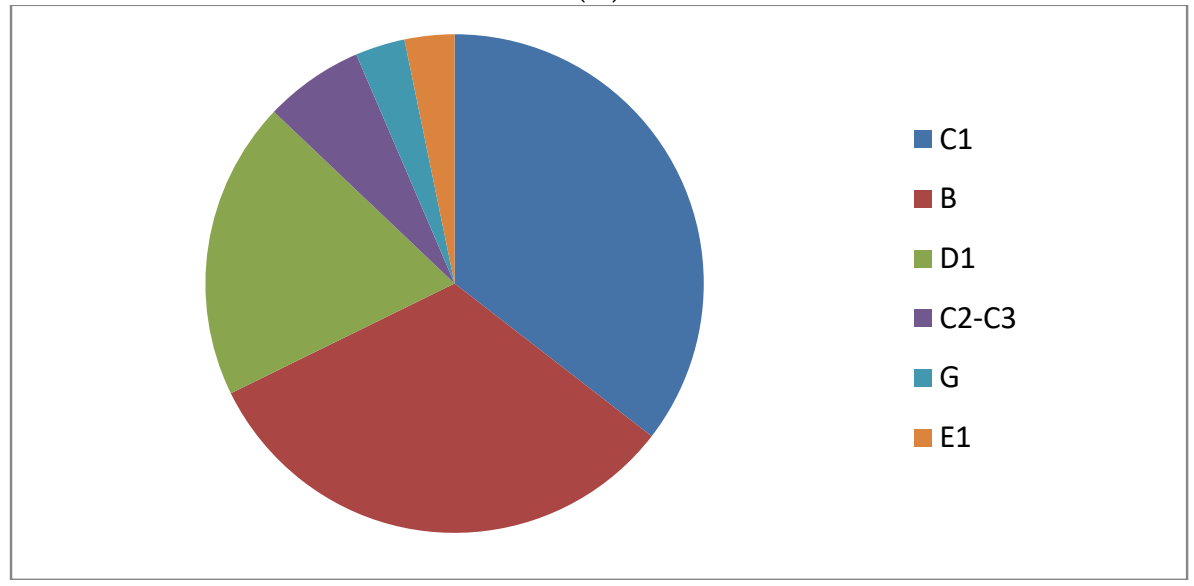

(B)

Figure 1. (A) Frequency of occurrence of Salmonella serotypes $(n=32)$. All isolates belonged to 11 serovars. The share (\%) of each serovar is represented as a ring diagram. (B) Categories of serogroups based on the serovars. Serogroup $\mathrm{C}_{1}$ : Rissen and Infantis. Serogroup B: Derby, Typhimurium, Indiana, and Reading. Serogroup $D_{1}$ : Enteritidis. Serogroup $C_{2}-C_{3}$ : Kentucky. Serogroup G: Idikan. Serogroup $E_{1}$ : Give.

The serovars were distributed among the different types of sample, indicating high genetic diversity of Salmonella strains occurring in the Russian Federation.

In general, these serovars fell into six serogroups $\left(C_{1}, B, D_{1}, C_{2}-C_{3}, G\right.$, and $\left.E_{1}\right)$. Serogroup $\mathrm{C}_{1}(35.48 \%, n=11)$ was the most common, followed by B $(32.26 \%, n=10), \mathrm{D}_{1}$ $(19.35 \%, n=6), \mathrm{C}_{2}-\mathrm{C}_{3}(6.45 \%, n=2), \mathrm{G}(3.23, n=1)$, and $\mathrm{E}_{1}(3.23 \%, n=1)$.

\subsection{Prevalence of Antimicrobial Resistance}

Research on the sensitivity of Salmonella isolates to antibiotics revealed various levels of resistance to 13 antimicrobial preparations (Table 2). The isolates were most commonly resistant to trimethoprim/sulfamethoxazole $(n=19,59.38 \%)$, cefazolin $(n=15,46.86 \%)$, 
tetracycline $(n=13,40.63 \%)$, and amikacin $(n=9,28.13 \%)$. They were most sensitive to amoxicillin-clavulanic acid $(n=30,93.75 \%)$, tobramycin $(n=26,81.25)$, ampicillin $(n=23$, $71.88 \%)$, and azithromycin $(n=20,62.50 \%)$.

Table 2. Antimicrobial resistance of Salmonella isolated from food products.

\begin{tabular}{|c|c|c|c|c|}
\hline \multirow{2}{*}{ Antimicrobial Class } & \multirow{2}{*}{ Antimicrobial Agent } & \multicolumn{3}{|c|}{ No. of Strains (\%) } \\
\hline & & Resistant (R) & Intermediate (I) & Susceptible (S) \\
\hline Penicillins & Ampicillin (AMP) & $8(25.00)$ & $8(3.13)$ & $23(71.88)$ \\
\hline Monobactams/carbapenems & Imipenem (IPM) & $6(18.75)$ & $2(6.25)$ & $24(75.00)$ \\
\hline \multirow{3}{*}{ Aminoglycosides } & Amikacin (AMK) & $9(28.13)$ & $14(43.75)$ & $9(28.13)$ \\
\hline & Streptomycin (STR) & $8(25.00)$ & $4(12.50)$ & $20(62.50)$ \\
\hline & Tobramycin & $5(15.63)$ & $1(3.13)$ & $26(81.25)$ \\
\hline \multirow{2}{*}{ Cephems } & Cefotaxime (CTX) & $6(18.75)$ & $6(18.75)$ & $20(62.50)$ \\
\hline & Cefazolin (CFZ) & $15(46.86)$ & $8(25.00)$ & $9(28.13)$ \\
\hline \multirow[t]{2}{*}{ Folate pathway antagonists } & $\begin{array}{c}\text { Trimethoprim/ } \\
\text { sulfamethoxazole (SXT) }\end{array}$ & $19(59.38)$ & $0(0)$ & $13(40.63)$ \\
\hline & Chloramphenicol (CHL) & $7(21.88)$ & $3(9.38)$ & $22(68.75)$ \\
\hline Macrolides and azalides & Azithromycin & $12(37.50)$ & - & $20(62.50)$ \\
\hline $\begin{array}{l}\beta \text {-Lactam } / \beta \text {-lactamase } \\
\text { inhibitor combinations }\end{array}$ & $\begin{array}{l}\text { Amoxicillin-clavulanic acid } \\
\text { (AMC) }\end{array}$ & $2(6.25)$ & $0(0)$ & $30(93.75)$ \\
\hline Nitrofuran & Furadonin & $5(18.75)$ & $3(9.38)$ & $24(75.00)$ \\
\hline \multirow[t]{2}{*}{ Tetracyclines } & Tetracycline (TET) & $13(40.63)$ & $9(28.13)$ & $10(31.25)$ \\
\hline & $\begin{array}{l}\text { Keys: ampicillin (AMP) } 10 \mu \mathrm{g}, \\
\text { tobramycin } 10 \mu \mathrm{g} \text {, cefotaxime }(C \\
1.25 / 23.75 \mu \mathrm{g} \text {, chloramphenicol } 30 \\
300 \mu \mathrm{g} \text {, and tetracycline (TET) } 30\end{array}$ & $\begin{array}{l}\text { nem (IPM) } 10 \mu \\
30 \mu \mathrm{g}, \text { cefazolir } \\
\text { zithromycin } 15 \mu\end{array}$ & $\begin{array}{l}\text { kacin (AMK) } 10 \mu \mathrm{g}, \\
30 \mu \mathrm{g}, \text { trimethopri } \\
\text { cillin-clavulanic acid }\end{array}$ & $\begin{array}{l}\text { tomycin (STR) } 10 \\
\text { lfamethoxazole (S } \\
\text { C) } 20 / 10 \mu \mathrm{g} \text {, furado }\end{array}$ \\
\hline
\end{tabular}

Resistance to antimicrobial preparations varied between serotypes (Table 3). In general, resistance was higher among the Salmonella serotypes often causing salmonellosis in humans, rather than in less common serotypes. S. Typhimurium was most often resistant to streptomycin (75\%), trimethoprim/sulfamethoxazole (75\%), tetracycline (75\%), azithromycin (50\%), and cefazolin (50\%); all strains were, however, resistant to amikacin and amoxicillin + clavulanic acid. S. Enteritidis isolates were resistant to cefazolin (50\%), trimethoprim/sulfamethoxazole (50\%), azithromycin (33\%), and tetracycline (33\%); at the same time, all strains were sensitive to streptomycin, tobramycin, amoxicillin + clavulanic acid, and nitrofurantoin. The most represented serotype, Infantis, was resistant to all antibiotics tested. In $S$. Infantis isolates, the highest percentage of resistance was shown for trimethoprim/sulfamethoxazole (66.7\%) and tetracycline (55.6\%). Resistance to cephalosporins was also revealed. The highest resistance to cefazolin was observed among $S$. Give (100\%), S. Reading (66.7\%), S. Typhimurium (50\%), S. Enteritidis (50\%), and S. Kentucky (50\%). S. Derby (50.0\%), S. Enteritidis (33.3\%), and S. Reading (33.3\%) were most often resistant to cefotaxime. 
Table 3. Resistance of various Salmonella strains to antimicrobial preparations.

\begin{tabular}{|c|c|c|c|c|c|c|c|c|c|c|c|c|}
\hline \multirow[b]{2}{*}{ 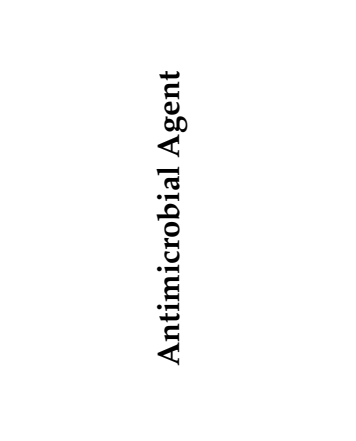 } & \multicolumn{12}{|c|}{ No. of Resistance Isolates by Serotype (Resistance Rate, \%) } \\
\hline & 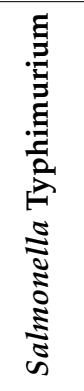 & 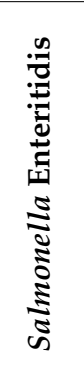 & 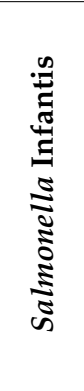 & 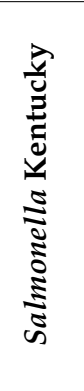 & 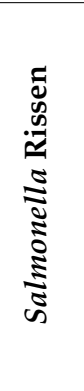 & 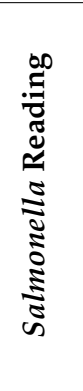 & 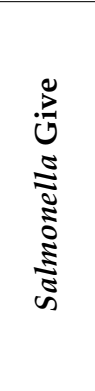 & 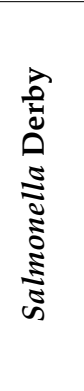 & 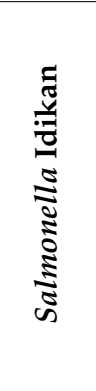 & 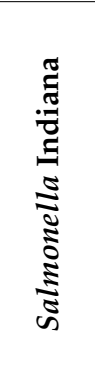 & 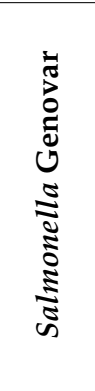 & 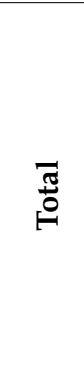 \\
\hline Ampicillin (AMP) & 25.0 & 16.7 & 33.3 & 0.0 & 50.0 & 0.0 & 100.0 & 0.0 & 0.0 & 100.0 & 0.0 & 25.0 \\
\hline Imipenem (IPM) & 25.0 & 16.7 & 33.3 & 50.0 & 0.0 & 0.0 & 0.0 & 0.0 & 0.0 & 0.0 & 0.0 & 18.8 \\
\hline Amikacin (AMK) & 0.0 & 16.7 & 33.3 & 0.0 & 50.0 & 66.7 & 0.0 & 50.0 & 0.0 & 100.0 & 0.0 & 28.1 \\
\hline Streptomycin (STR) & 75.0 & 0.0 & 33.3 & 0.0 & 0.0 & 0.0 & 0.0 & 50.0 & 0.0 & 100.0 & 0.0 & 25 \\
\hline Tobramycin (TM) & 25.0 & 0.0 & 22.2 & 0.0 & 0.0 & 0.0 & 0.0 & 50.0 & 0.0 & 100.0 & 0.0 & 15.6 \\
\hline Cefotaxime (CFX) & 25.0 & 33.3 & 11.1 & 0.0 & 0.0 & 33.3 & 0.0 & 50.0 & 0.0 & 0.0 & 0.0 & 18.8 \\
\hline Cefazolin (CFZ) & 50.0 & 50.0 & 44.4 & 50.0 & 50.0 & 66.7 & 100.0 & 50.0 & 0.0 & 0.0 & 0.0 & 50 \\
\hline $\begin{array}{l}\text { Trimethoprim/sulfame- } \\
\text { thoxazole (STX) }\end{array}$ & 75.0 & 50.0 & 66.7 & 50.0 & 50.0 & 33.3 & 100.0 & 50.0 & 0.0 & 100.0 & 100.0 & 59.34 \\
\hline Chloramphenicol (CHL) & 25.0 & 16.7 & 44.4 & 0.0 & 50.0 & 0.0 & 0.0 & 0.0 & 0.0 & 0.0 & 0.0 & 21.9 \\
\hline Azithromycin (AZM) & 50.0 & 33.3 & 22.2 & 0.0 & 50.0 & 33.3 & 0.0 & 50.0 & 100.0 & 0.0 & 100.0 & 34.4 \\
\hline $\begin{array}{c}\text { Amoxicillin + clavulanic } \\
\text { acid (AMK) }\end{array}$ & 0.0 & 0.0 & 22.2 & 0.0 & 0.0 & 0.0 & 0.0 & 0.0 & 0.0 & 0.0 & 0.0 & 6.3 \\
\hline Nitrofurantoin (NIT) & 0.0 & 0.0 & 44.4 & 0.0 & 0.0 & 33.3 & 0.0 & 0.0 & 0.0 & 0.0 & 0.0 & 15.6 \\
\hline Tetracycline (TET) & 75.0 & 33.3 & 55.6 & 0.0 & 0.0 & 33.3 & 0.0 & 50.0 & 0.0 & 100.0 & 0.0 & 40.6 \\
\hline
\end{tabular}

In total, 30 resistance patterns of these Salmonella isolates to eight groups of antimicrobial agents were found (Table 4).

Table 3 shows that only two of the studied strains $(6.25 \%)$ were sensitive to all tested antimicrobial preparations. The remaining $93.75 \%$ were resistant to at least one class of antimicrobial preparation, while $68.75 \%$ of the strains exhibited multiple resistance to three or more classes of antimicrobial agents. Among the studied isolates, $15.63 \%(5 / 32)$ were resistant against four groups of antimicrobial agents, while $25 \%(8 / 32)$ exhibited resistance to four individual preparations.

Three of the studied isolates exhibited the highest resistance. SZL 38 was resistant to six antibiotics belonging to four groups of antimicrobial compounds, while SZL 30 and SZL 31 were resistant to eight of the antimicrobial compounds belonging to six groups.

Table 4. Phenotypic antibiotic resistance profiles of Salmonella serotypes.

\begin{tabular}{ccccc}
\hline Serovar & Isolate & Pattern & $\begin{array}{c}\text { No. of Antimicrobial } \\
\text { Agents }\end{array}$ & No. of Classes \\
\hline Salmonella Give & S1 & AMP-STX-CFZ & 3 & 3 \\
\hline \multirow{2}{*}{$\begin{array}{c}\text { Salmonella } \\
\text { Typhimurium }\end{array}$} & S3 & STR-AMP-TM-IPM-CHL & 5 & 4 \\
\cline { 2 - 5 } & S5 & CTX-STX-AZM-TET-CFZ & 5 & 4 \\
\cline { 2 - 5 } & S14 & STR-STX-AZM-TET-CFZ & 5 & 3 \\
\hline
\end{tabular}


Table 4. Cont.

\begin{tabular}{|c|c|c|c|c|}
\hline Serovar & Isolate & Pattern & $\begin{array}{c}\text { No. of Antimicrobial } \\
\text { Agents }\end{array}$ & No. of Classes \\
\hline \multirow{3}{*}{ Salmonella Reading } & $\mathrm{S} 23$ & CTX-AMK-AZM-CFZ & 4 & 3 \\
\hline & S4 & AMK-STX-AZM-TET-NIT & 5 & 5 \\
\hline & S33 & CFZ & 1 & 1 \\
\hline \multirow{2}{*}{ Salmonella Derby } & S6 & STR-AMK-AZM-TET & 4 & 3 \\
\hline & S11 & CTX-TM-STX-CFZ & 4 & 3 \\
\hline Salmonella Idikan & S9 & AZM & 1 & 1 \\
\hline \multirow{2}{*}{ Salmonella Rissen } & S10 & CFZ-CHL & 1 & 1 \\
\hline & S18 & AMP-AMK-STX-AZM & 4 & 4 \\
\hline \multirow{9}{*}{ Salmonella Infantis } & S26 & STR-IPM-CFZ-NIT & 4 & 4 \\
\hline & S15 & AMK-STX-AZM-TET-CFZ & 5 & 5 \\
\hline & SZL 30 & $\begin{array}{c}\text { STR-AMP-AMK-TM-STX- } \\
\text { IPM-TET-CHL }\end{array}$ & 8 & 6 \\
\hline & SZL 31 & $\begin{array}{l}\text { STR-AMP-AMK-TM-STX- } \\
\text { IPM-TET-CHL }\end{array}$ & 8 & 6 \\
\hline & S34 & AMK-STX-TET-CFZ-NIT & 5 & 5 \\
\hline & S35 & STX & 1 & 1 \\
\hline & S36 & ND & 0 & 0 \\
\hline & S37 & STX-TET-NIT & 3 & 3 \\
\hline & $\mathrm{S} 28$ & CTX-AZM-CFZ-CHL-NIT & 5 & 4 \\
\hline Salmonella Genovar & S16 & STX-AZM & 2 & 2 \\
\hline \multirow{6}{*}{ Salmonella Enteritidis } & S7 & AMK-AZM-CFZ & 3 & 3 \\
\hline & S8 & CTX-AZM & 2 & 2 \\
\hline & $\mathrm{S} 17$ & AMP-STX-TET-CFZ-CHL & 5 & 5 \\
\hline & S20 & STX-IPM-CFZ & 3 & 3 \\
\hline & S27 & CTX-TET & 2 & 2 \\
\hline & S29 & STX & 1 & 1 \\
\hline \multirow{2}{*}{ Salmonella Kentucky } & S32 & ND & 0 & 0 \\
\hline & S19 & STX-IMP-CFZ & 3 & 3 \\
\hline $\begin{array}{c}\text { Salmonella } \\
\text { Typhimurium }\end{array}$ & SZL 38 & $\begin{array}{c}\text { STR-AMP-AMK-TM-STX- } \\
\text { TET }\end{array}$ & 6 & 4 \\
\hline
\end{tabular}

Keys: ampicillin (AMP) $10 \mu \mathrm{g}$, imipenem (IPM) $10 \mu \mathrm{g}$, amikacin (AMK) $10 \mu \mathrm{g}$, streptomycin (STR) $10 \mu \mathrm{g}$, tobramycin $10 \mu \mathrm{g}$, cefotaxime (CTX) $30 \mu \mathrm{g}$, cefazolin (CFZ) $30 \mu \mathrm{g}$, trimethoprim/sulfamethoxazole (SXT) 1.25/23.75 $\mu \mathrm{g}$, chloramphenicol $30 \mu \mathrm{g}$, azithromycin $15 \mu \mathrm{g}$, amoxicillin-clavulanic acid (AMC) 20/10 $\mu \mathrm{g}$, furadonin $300 \mu \mathrm{g}$, and tetracycline (TET) $30 \mu \mathrm{g}$.

\subsection{Sequencing}

Sequencing was carried out for three multiply resistant strains: S. enterica serovar Infantis isolates SZL 30 and SZL 31, and S. Typhimurium SZL 38, which exhibited resistance to at least six antibiotics. The technologies used were Illumina (Illumina, San Diego, CA, USA) and single-molecular nanopore sequencing (Oxford Nanopore, Oxford, UK). The results for sequencing of genomic DNA libraries of the studied Salmonella strains are presented in Supplementary Table S1.

Assembling the contigs for each strain resulted in a complete circular chromosome sequence and a set of ring-shaped contigs representing the plasmids. Thus, the chromosome 
size of the sequenced strains was from 4.68 to $5.05 \times 10^{6} \mathrm{nt}$, while the number of plasmids varied from one to two, depending on the strain (Table 5).

Table 5. Genomes of the Salmonella strains.

\begin{tabular}{cccc}
\hline \multirow{2}{*}{ Strain } & \multirow{2}{*}{ Chromosome Size (bp) } & \multicolumn{2}{c}{ Plasmids } \\
\cline { 3 - 4 } & & Name & Size (bp) \\
\hline \multirow{2}{*}{ SZL 30 } & \multirow{2}{*}{$4,689,375$} & pSZL30.1 & 276,251 \\
& \multirow{2}{*}{ SZL 31 } & pSZL30.2 & 53,986 \\
\hline \multirow{2}{*}{ SZL 38 } & \multirow{2}{*}{$5,689,704$} & pSZL31.1 & 280,239 \\
& $5,052,615$ & pSZL31.2 & 53,147 \\
\hline
\end{tabular}

\subsection{General Characterization of the Genomes}

Analysis of the genomes of Salmonella strains SZL 30, SZL 31, and SZL 38 revealed that they contained 5078 to 5209 protein-encoding genes, with $73 \%$ of them being genes with predicted function. All sequenced genomes contained eight copies of 5S rRNA, seven copies each of $16 \mathrm{~S}$ rRNA and $23 \mathrm{~S}$ rRNA, and 84 to 89 tRNA (Table 6).

Table 6. General characteristics of the Salmonella genomes.

\begin{tabular}{cccc}
\hline \multirow{2}{*}{ Parameter } & \multicolumn{3}{c}{ Strain } \\
\cline { 2 - 4 } & $\mathbf{3 0}$ & $\mathbf{3 1}$ & $\mathbf{3 8}$ \\
\hline Predicted genes & 5184 & 5191 & 5320 \\
\hline Protein-coding genes & 5078 & 5085 & 5209 \\
\hline $\begin{array}{c}\text { Protein-coding genes with } \\
\text { predicted function }\end{array}$ & 3845 & 3785 & 3851 \\
\hline tRNA genes & $(75.7 \%)$ & $(74.4 \%)$ & $(73.9 \%)$ \\
\hline
\end{tabular}

\subsection{Multilocus Sequence Typing of Strains}

From analysis of the genomes of the Salmonella strains SZL 30, SZL 31, and SZL 38 using the Salmonella In Silico Typing Resource (SISTR) and SeqSero2, it was established that SZL 30 and SZL 31 belong to the serovar Infantis, and SZL 38 to the serovar Typhimurium.

\subsection{Antibiotic Resistance Genes}

Genome analysis of Salmonella strains SZL 30, SZL 31, and SZL 38 using the CARD and ResFinder 4.1 databases revealed that these strains possessed genes of resistance to streptomycin (aadA1-SZL 30, aadA2b-SZL 31, aph(3")-Ib and aph(6)-Id-SZL 38), ampicillin, amoxicillin, cefazolin, piperacillin, and ticarcillin $\left(b l a_{T E M-1 B}\right)$, amikacin and tobramycin $\left(a a c\left(6^{\prime}\right)-I a a\right)$, sulfamethoxazole (sul3-SZL 30 and SZL 31; sul2-SZL 38), trimethoprim (dfrA14-SZL 30 and SZL 31), doxycycline and tetracycline (tet(A)-SZL 30 and SZL 31; tet(B)_SZL 38), chloramphenicol (cmlA1), rifampicin, erythromycin, and azithromycin $(m e f B$-SZL 30 and SZL 31), puromycin and erythromycin $(m d f A / c m r)$, novobiocin, nalidixic acid, and norfloxacin ( $m d t A B C$-tolC).

\subsection{Plasmids}

Salmonella strain SZL 30 possessed an F-type conjugative plasmid pSZL30.1 (276,251 nt), bearing the genes of antibiotic resistance $d f r A 14$ and tet $A$. pSZL30.1 belongs to the IncFIB incompatibility group and contains four toxin-antitoxin loci $(c c d A / c c d B, v a p B / v a p C, r e l B / r e l E$, and pemI/pemK), which are responsible for its stable inheritance in the population due to the mechanism of post-segregational killing. The conjugative Ti-type plasmid pSZL30.2 $(53,986 \mathrm{nt})$ contains the sat1, cmlA1, aadA1, sul3, and bla $a_{T E M-1 B}$ resistance genes, belongs to the IncX1 incompatibility group, and contains the $\mathrm{relB} / \mathrm{relE}$ toxin-antitoxin locus. 
The Salmonella strain SZL 31 possessed an F-type conjugative plasmid pSZL31.1 $(280,239 \mathrm{nt})$, bearing the sat1, cmlA1, sul3, tet $A$, aadA2b, and $d$ frA14 genes of antibiotic resistance. pSZL31.1 belongs to the IncFIB incompatibility group and contains four toxinantitoxin loci $(c c d A / c c d B, \operatorname{vapB} / \operatorname{vap} C, \mathrm{relB} / \mathrm{relE}$, and pemI/pemK). The Ti-type conjugative plasmid pSZL31.2 (53,147 nt) of the IncX1 incompatibility group contains the relB $/ \mathrm{relE}$ toxin-antitoxin locus and bears the genes of antibiotic resistance $c m l A 1$, sul3, and $b l a_{T E M-1 B}$.

Strain Salmonella SZL 38 possessed the plasmid pSZL38.1 belonging to the p0111 incompatibility group and containing the relB/relE toxin-antitoxin locus. Comparison of the nucleotide sequence of pSZL38.1 to GenBank sequences revealed 98.84\% homology to $\mathrm{pD} 72 \mathrm{C}$ of E. coli strain D72C [20], which may indicate horizontal gene transfer in the family Enterobacteriaceae.

\subsection{Pathogenicity Islands}

Comparison of the nucleotide sequences of pathogenicity islands [21-23] with the genomes of the sequenced strains revealed that the genomes of Salmonella strains SZL 30, SZL 31, and SZL 38 contained the following full-sized pathogenicity islands: SPI-1, SPI-2, SPI-4, SPI-5, SPI-9, SPI-11, SPI-13, SPI-14, and CS54 (Supplementary Table S2). The genome of strain SZL 38 also contained the full-sized pathogenicity islands SPI-3, SPI-6, SPI-12, and SPI-16, while the genomes of strains SZL 30 and SZL 31 lacked some of the genes involved in the above pathogenicity islands (Supplementary Table S3). Pathogenicity islands SPI-7, SPI-8, SPI-10, SPI-15, SPI-18, SPI-19, SPI-20, SPI-21, SPI-22, and SPI-23 were not found in the genomes of Salmonella strains SZL 30, SZL 31, and SZL 38.

\subsection{Prophages}

Analysis of the presence of prophages in the sequenced genomes using the PHASTER software package revealed 14 prophages in the genome of Salmonella SZL 30 and 13 prophages in the genomes of both Salmonella SZL 31 and Salmonella SZL 38 (Supplementary Table S2). The prophages SZL 30-1, SZL 30-2, SZL 30-3, SZL 30-4, SZL 31-1, SZL 31-2, SZL 31-3, SZL 31-4, SZL 38-1, SZL 38-1, SZL 38-2, SZL 38-3, SZL 38-4, SZL 38-5, and SZL 38-6 were intact, while the remaining ones were dubious or incomplete (Supplementary Table S3).

Comparison of the sequences of these prophages with the GenBank data revealed most of them to be widespread in the genomes of previously sequenced Salmonella strains. The sequences of 32 out of 40 revealed prophages exhibiting over 99\% homology to the database sequences at coverage of over 99\% (Supplementary Table S3).

\section{Discussion}

Salmonellosis is considered a serious public healthcare issue worldwide [24]. The emergence of Salmonella strains with multiple drug resistance is an important problem in terms of human health and may result in inefficient treatment [25]. Salmonella spp. are among the main pathogens causing food poisoning in the Russian Federation and the third most important ones in the structure of the nidi of group diseases with faecal-oral transmission mechanisms. In 2020, 20 outbreaks of salmonellosis group infection were revealed (compared to 70 in 2019), which affected 422 people [4].

The overall prevalence of Salmonella in this study was $6.8 \%$. In general, the high isolation rate of Salmonella spp. in chicken samples indicates that chicken is one of the most important sources of human salmonellosis.

In the present work, 32 bacterial isolates were obtained and identified as Salmonella strains based on their biochemical characteristics. The most common serovar was Infantis $(28.13 \%, n=9)$. S. Infantis is considered one of the most frequent causes for bacterial food poisoning worldwide $[26,27]$. Its high occurrence $(25.8 \%)$ was revealed by serotyping of the Salmonella isolates from food carried out in Turkey [28].

The second most common serovar was Enteritidis $(18.75 \%, n=6)$. S. enterica serotype Enteritidis ( $S$. Enteritidis) is the most common Salmonella serotype worldwide, especially in retail meat products $[29,30]$ and seafood [31]. Recent reports from Brazil, Poland, Malaysia, 
China, and Greece showed that Enteritidis was the dominant serovar with frequency of occurrence from $34 \%$ to $86 \%$, which indicates a broad distribution worldwide [32-35].

The third most common serovar was Typhimurium. Among the major serovars, $S$. Typhimurium is mostly responsible for diarrhoea in humans [36]. In the present work, four isolates were identified as $S$. Typhimurium. This serotype was recently acknowledged as a new healthcare problem, since it has been isolated from various animals, environmental objects, and food; moreover, the frequency of human diseases caused by this organism in various countries is increasing [37-39].

These results are in complete agreement with the data from the report by the Russian Federal Service for Surveillance on Consumer Rights Protection and Human Wellbeing, since in 2015-2020 the predominant serotypes in Russian territory were $S$. Enteritidis $(64.7 \%), S$. Typhimurium (4.8\%), and S. Infantis (3.2\%). S. Infantis was most common in chicken meat, $S$. Kentucky in turkey meat, and $S$. Typhimurium in environmental objects and pork [4].

In most cases, salmonellosis is cured by itself, with antimicrobial therapy required only for invasive or long-term infections. However, large-scale application of antibiotics results in the development of resistance to antimicrobial preparations and favours the emergence of strains possessing multiple drug resistance (MDR) [40-42].

The Salmonella strains isolated in our work were tested for their sensitivity to 13 antimicrobial preparations significant for healthcare and veterinary medicine. Only two of the studied strains $(6.25 \%)$ were sensitive to all tested antimicrobial agents. In total, $93.75 \%$ of the isolates were resistant to at least one class of antimicrobial preparations, while $68.75 \%$ exhibited MDR to three or more classes of antimicrobial agents. Multiple resistance implies simultaneous resistance to three or more antibiotics. Other researchers have also reported a high percentage of antibiotic-resistant Salmonella strains isolated from food [43-45]. Animals are the main reservoir of Salmonella, and irresponsible application of antimicrobial preparations to cure productive animals, for disease prevention, and for growth stimulation results in the emergence of resistant pathogens. Increased occurrence of human salmonellosis caused by food infected with Salmonella strains resistant to antimicrobial agents has been reported [46,47].

Investigation of the sensitivity of our Salmonella isolates to antimicrobial preparations showed that the greatest number of isolates were resistant to folate pathway antagonists (trimethoprim/sulfamethoxazole), followed by cephems (cefazolin) and the tetracycline group (tetracycline). High resistance to these groups of antibiotics is in agreement with previous reports [48,49], which emphasized uncontrolled application of these antibacterial preparations. Resistance of 31 Salmonella strains isolated from poultry samples in Ethiopia was $60 \%$ [48]. Most studied isolates were sensitive to amoxicillin/clavulanic acid, imipenem, ampicillin, and streptomycin.

All S. Infantis isolates were resistant to at least one antibiotic, with the highest resistance observed for trimethoprim/sulfamethoxazole, tetracycline, chloramphenicol, and cefazolin. The $S$. Enteritidis isolates were most often resistant to trimethoprim/sulfamethoxazole, cefazolin, azithromycin, and tetracycline.

S. Typhimurium was most resistant to streptomycin, trimethoprim/sulfamethoxazole, tetracycline, and azithromycin. All studied S. Typhimurium and S. Enteritidis strains were sensitive to nitrofurantoin and amoxicillin + clavulanic acid.

Our findings of high resistance to trimethoprim/sulfamethoxazole are similar to the results obtained previously [50] for S. enterica serovars isolated in Egypt from broiler chickens and chicken carcasses, as well as for Salmonella isolates from chicken carcasses sold in Ibagué, Columbia [51].

The high levels of antibiotic resistance of Salmonella food isolates revealed in the present work indicate non-selective and constant application of higher than therapeutic doses of antibiotics to animals.

Antimicrobial resistance (AMR) poses a colossal threat to global health and incurs high economic costs to society. This ever-growing problem not only threatens public health, 
but also incurs a huge toll on a nation's economic growth by delayed hospitalizations, lengthening recovery time, expensive medicines, and specialized care for patients [10-12]. Authors have estimated the economic cost of resistance per antibiotic by drug class and compared those in developing and developed countries, like in Thailand and the United States [52]. The total economic cost of AMR due to resistance in five pathogens, S. aureus, E. coli, K. pneumoniae, A. baumannii, and P. aeruginosa was $\$ 0.5$ billion and $\$ 2.9$ billion in Thailand and the US, respectively. So, resistance has a significant impact on the cost of treatments [11]. Increased illness coupled with limited options for treatment further strains low-income settings already struggling with low resources.

Antibiotic-resistant infections also affect animals, and the increasing rates of resistance also mean that it becomes more difficult to treat such infections. Death to livestock can further damage the finances of both individual citizens and society. Novel treatments for MDR infections can cost up to tens of thousands of US dollars, which ultimately makes the medicines unreachable for many [6]. Understanding the depth of the problem of the prevalence of resistance, especially multiple resistance, primarily among pathogenic microorganisms can result in better-informed policy recommendations regarding interventions that affect antimicrobial consumption and those aimed specifically at reducing the burden of AMR.

In the second stage of the work, Salmonella strains selected in the previous stage (SZL 30, SZL 31, and SZL 38) were sequenced. Genomic analysis of the sequenced strains revealed the genes responsible for antibiotic activity, and their localization was determined.

The Salmonella strains SZL 30, SZL 31, and SZL 38 were found to be streptomycinresistant (Table 3).

Aminoglycoside resistance in Salmonella is also related to the expression of drugmodifying enzymes. These enzymes are classified into three main groups, according to the type of reaction they catalyse: acetyltransferases, encoded by the aac genes, phosphotransferases encoded by aph genes, and nucleotidyltransferases, encoded by aadA genes. Many variations of genes in each class are described [53]. In this study, all the strains had at least one of the three classes of genes described.

Strain SZL 38 had two different genes associated with resistance to aminoglycosides localized in chromosomes. Previously, it has been reported that there are different variants of resistance to aminoglycosides in the same strains isolated from the poultry production chain $[42,51]$. This may be due to the intense selection pressure in these production lines.

Resistance of Salmonella strain SZL 30 was probably caused by the aadA1 gene localized in the plasmid pSZL30.2 and encoding aminoglycoside-3'-adenylyl transferase, which inactivates streptomycin or spectinomycin by adenylation (Table 7). The nucleotide sequence of aadA1 was $100 \%$ identical to the previously described aadA1 gene (JQ414041.1) from Pseudomonas aeruginosa strain K7 [54]. Streptomycin resistance of Salmonella strain SZL 31 may be due to the presence of the $a a d A 2 b$ gene localized in the plasmid pSZL31.1 and also encoding aminoglycoside-3'-adenylyl transferase. The nucleotide sequence of the previously described $a a d A 2 b$ gene (D43625.1) from the plasmid pSA1700 of $P$. aeruginosa strain ST1700, which provides Escherichia coli cells with streptomycin resistance [55], differs by one pointwise replacement from the $a a d A 2 b$ gene of the plasmid pSZL31.1. Streptomycin resistance of Salmonella strain SZL 38 may be caused by the presence of the aph(3")-Ib and aph(6)-Id genes, encoding aminoglycoside phosphotransferases, which inactivate a number of aminoglycoside antibiotics by phosphorylation, in the chromosome of this strain. The nucleotide sequence of the $a p h\left(3^{\prime \prime}\right)-I b$ gene was $100 \%$ identical to that of the previously described aph(3")-Ib gene (AF321551.1) from the plasmid pSTR1 of Shigella flexneri strain 2731 [56]. The nucleotide sequence of the aph(6)-Id gene was $100 \%$ identical to that of the previously described aph(6)-Id gene (M28829.1) from the plasmid pRSF1010 of an E. coli strain [57]. 
Table 7. Antibiotic resistance genes in the Salmonella genomes.

\begin{tabular}{|c|c|c|c|c|c|}
\hline \multirow{2}{*}{ Resistance Gene } & \multirow{2}{*}{ Protein } & \multirow{2}{*}{ Antimicrobial Agent } & \multicolumn{3}{|c|}{ Location } \\
\hline & & & SZL 30 & SZL 31 & SZL 38 \\
\hline $\operatorname{aad} A 1$ & \multirow{2}{*}{$\begin{array}{l}\text { Aminoglycoside }\left(3^{\prime \prime}\right) \\
\text { (9)-adenylyltransferase }\end{array}$} & \multirow{4}{*}{ STR } & pSZL30.2 & - & - \\
\hline$a a d A 2 b$ & & & - & pSZL31.1 & - \\
\hline $\operatorname{aph}\left(3^{\prime \prime}\right)-I b$ & $\begin{array}{c}\text { Aminoglycoside } \\
\text { 3'-phosphotransferase }\end{array}$ & & - & - & chromosome \\
\hline $\operatorname{aph}(6)-I d$ & $\begin{array}{c}\text { Aminoglycoside } \\
\text { O-phosphotransferase }\end{array}$ & & - & - & chromosome \\
\hline bla $_{T E M-1 B}$ & Class A $\beta$-lactamase & AMP & pSZL30.2 & pSZL31.2 & chromosome \\
\hline $\operatorname{aac}\left(6^{\prime}\right)-I a a$ & $\begin{array}{l}\text { Chromosomal encoded } \\
\text { aminoglycoside } \mathrm{N} \\
\left(6^{\prime}\right) \text {-acetyltransferase }\end{array}$ & AMK, TM & chromosome & chromosome & chromosome \\
\hline sul3 & \multirow[t]{2}{*}{ Dihydropteroate synthase } & \multirow[t]{2}{*}{ STX } & pSZL30.2 & $\begin{array}{l}\text { pSZL31.1 } \\
\text { pSZL31.2 }\end{array}$ & - \\
\hline sul2 & & & - & - & chromosome \\
\hline $\operatorname{tet}(A)$ & \multirow{2}{*}{$\begin{array}{l}\text { Tetracycline efflux MSF } \\
\text { transporter }\end{array}$} & \multirow{2}{*}{ TET } & pSZL30.1 & pSZL31.1 & - \\
\hline $\operatorname{tet}(B)$ & & & - & - & chromosome \\
\hline cmlA1 & $\begin{array}{c}\text { Drug efflux MSF transporter } \\
\text { Bcr/CflA family }\end{array}$ & CHL & pSZL30.2 & $\begin{array}{l}\text { pSZL31.1 } \\
\text { pSZL31.2 }\end{array}$ & - \\
\hline$m e f B$ & MSF efflux transporter & AZM, ERY & pSZL30.2 & $\begin{array}{l}\text { chromosome } \\
\text { pSZL31.2 }\end{array}$ & - \\
\hline$m d f A / c m r$ & MSF efflux transporter & RIF, PUR, ERY & chromosome & chromosome & chromosome \\
\hline$m d t A B C$-tolC & MSF efflux transporter & NB, NAL, NOR & chromosome & chromosome & chromosome \\
\hline
\end{tabular}

The formation of genetic resistance to streptomycin in all three strains may be associated with the intensive use of streptomycin in animal husbandry, as evidenced by the results of a study of 66 meat samples of slaughter animals, in which a relatively high concentration of streptomycin was detected $-5 \times 10^{-1}$ (from $3 \times 10^{-1}$ to $8 \times 10^{-1}$ ) $\mathrm{mg} / \mathrm{kg}$ at a limit of $0.2 \mathrm{mg} / \mathrm{kg}$ in the territory of the Russian Federation.

Resistance of Salmonella strains SZL 30, SZL 31, and SZL 38 to $\beta$-lactam antibiotics may be caused by the presence in the genomes of these strains of the bla $a_{T E M-1 B}$ gene, which is localized in the plasmids pSZL30.2 and pSZL31.2 and in the chromosome of strain SZL 38 (Table 7). The $b l a_{\text {TEM-1B }}$ gene encodes $\beta$-lactamase, which provides bacterial resistance to $\beta$-lactam antibiotics by hydrolysing them. The nucleotide sequences of all revealed $b l a_{T E M-1 B}$ genes were $100 \%$ homologous to each other and to the previously described bla $a_{T E M-1 B}$ gene (HM769901.1) from the plasmid pZM3 of an S. enterica subsp. enterica serovar Wien strain [58]. $\beta$-Lactamase hydrolyses the $\beta$-lactam ring, resulting in the formation of $\beta$-amino acids that do not have antimicrobial activity [59]. The presence of genetic resistance to lactamases, which are often used to treat humans, among Salmonella strains isolated from meat products indicates their use as a prophylaxis or for the treatment of animals [60]. Such strains circulating in animals can infect humans and transmit antibiotic resistance to other pathogens [61].

Resistance of Salmonella strains SZL 30, SZL 31, and SZL 38 to amikacin and tobramycin was probably caused by the presence of the $a a c\left(6^{\prime}\right)$-Iaa gene in the chromosomes of these strains. The $a a c\left(6^{\prime}\right)$-Iaa gene encodes aminoglycoside- $6^{\prime}$-acetyl transferase, which provides bacterial resistance to a number of aminoglycoside antibiotics by their acetylation. The nucleotide sequences of the aac (6')-Iaa genes located in the chromosomes of the Salmonella strains SZL 30 and SZL 31 were 100\% identical and 97.5\% homologous to the previously described aac(6')-Iaa gene (NC_003197.2) from Salmonella enterica subsp. enterica serovar 
Typhimurium str. LT2 [62]. The sequence of the aac(6')-Iaa gene localized in the chromosome of Salmonella strain SZL 38 was $100 \%$ identical to that of the previously described aac $\left(6^{\prime}\right)$-Iaa gene (NC_003197.2), which is known to provide E. coli cells with resistance to amikacin, tobramycin, and kanamycin [63].

Sulphonamide resistance in Gram-negative bacilli usually results from the acquisition of one of three sul1, sul2, and sul3 genes encoding forms of dihydropteroate synthase that are not inhibited by the drug. Resistance of the Salmonella strains SZL 30 and SZL 31 to sulfamethoxazole was due to the presence of the sul3 gene localized in the plasmids pSZL30.1, pSZL31.1, and pSZL31.2 and encoding the sulfamethoxazole-resistant dihydropteroate synthase (Table 7). Nucleotide sequences of the sul3 located in the plasmids pSZL30.1, pSZL31.1, and pSZL31.2 were 100\% homologous to each other and to the previously described sul3 gene (AJ459418) from the pVP440 plasmid of E. coli strain r10044, providing E. coli cells with sulfamethoxazole resistance [64]. Sulfamethoxazole resistance of Salmonella strain SZL 38 may be due to the presence of the sul2 gene encoding dihydropteroate synthase in the chromosome of this strain. The spread of the sul2 gene has increased over the years in other European countries [2,9], as it has often been reported that this gene is more widespread among clinical isolates of E. coli than the sul1 gene. The nucleotide sequence of the sul2 gene was $100 \%$ homologous to that of the previously described sul2 gene (HQ840942.1) for sulfamethoxazole resistance from the plasmid pSRC27-H of S. enterica strain SRC27 [65].

Trimethoprim resistance of Salmonella strains SZL 30 and SZL 31 was probably due to the presence of the $d f r A 14$ gene localized in the plasmids pSZL30.1 and pSZL31.1 and encoding the trimethoprim-resistant dihydrofolate reductase, which is responsible for synthesis of tetrahydrofolate from dihydrofolate (Table 7). The nucleotide sequences of the $d f r A 14$ located in the plasmids pSZL30.1 and pSZL31.1 were $100 \%$ homologous to each other and to the previously described $d f r A 14$ gene (AJ313522.1) from the plasmid pSTOJO1 of a uropathogenic E. coli strain, which provides trimethoprim resistance to E. coli cells [66].

Resistance of the Salmonella strains SZL 30 and SZL 31 to tetracycline may be caused by the presence of the tet $(A)$ gene localized in the plasmids pSZL30.1 and pSZL31.1 and encoding the MSF transporter, providing resistance to the tetracycline group antibiotics by removing these compounds from the cell (Table 7). The tet $(A)$ and tet $(B)$ genes were more associated with tetracycline resistance, which is consistent with previous studies [6,14].

The nucleotide sequences of the tet $(A)$ genes localized in the plasmids pSZL30.1 and pSZL31.1 were $100 \%$ homologous to each other and to the previously described tet $(A)$ gene (AJ517790.2) from the plasmid pRAS1 of Aeromonas salmonicida strain 2402, which provides E. coli with resistance to the tetracycline group antibiotics $[67,68]$. Tetracycline resistance of Salmonella strain SZL 38 was probably caused by the presence in its chromosome of the tet $(B)$ gene, which also encodes the MSF transporter, providing resistance to tetracycline group antibiotics by removing these compounds from the cell. The nucleotide sequence of the $\operatorname{tet}(B)$ gene differed by one pointwise replacement from the previously described tet $A(B)$ gene (P02980.1) of tetracycline resistance from the Tn10 transposon [69].

Salmonella strains SZL 30 and SZL 31, unlike strain SZL 38, were found to be resistant to chloramphenicol (Table 7). Chloramphenicol resistance of the Salmonella strains SZL 30 and SZL 31 was probably caused by the presence of the $c m l A 1$ gene located in the plasmids pSZL30.1, pSZL31.1, and pSZL31.2 and encoding the MSF transporter of the $\mathrm{Bcr} / \mathrm{CflA}$ family, which is responsible for bacterial resistance to chloramphenicol due to its release from the cell. The nucleotide sequences of the $c m l A 1$ genes localized in the plasmids pSZL30.1, pSZL31.1, and pSZL31.2 were 100\% homologous to each other and to the previously described cmlA1 gene (U12338.3) from the plasmid R1033 of a P. aeruginosa strain, which provides E. coli cells with chloramphenicol resistance [70].

Thus, as a result of our study, it was found that strains SZL 30 and SZL 31 are resistant to the following antibiotics: STR, AMP, AMK, TM, STX, IPM, TET, and CHL, which correlated with the identified genetic elements fixed in the genome or localized in plasmids. However, the revealed phenotypic resistance to imipenem has not been confirmed at the 
genetic level; it is possible that the genetic determinants of resistance to imipenems may be non-specific carrier genes. We have shown the phenotypic resistance of strain SZL 38 to the following antibiotics: streptomycin (STR), ampicillin (AMP), amikacin (AMK), tobramycin (TM), trimethoprim/sulfamethoxazole (STX), and tetracycline (TET). There was a 100\% correlation between the phenotypic and genotypic data for strain SZL 38. From analysis of the genomes of these strains, genetic determinants were identified, presumably responsible for resistance to STR, AMP, AMK, and TET. The gene $d f r A 14$, responsible for resistance to trimethoprim, was not found; it is possible that the genetic determinants of resistance to trimethoprim may be non-specific transporter genes.

The high prevalence of aadA1, aadA2b, aph(3")-Ib, bla $a_{T E M-1 B}, \operatorname{tet}(A), \operatorname{tet}(B)$, and $c m l A 1$ genes in Salmonella isolates may be due to the common use of aminoglycosides, phenicols, $\beta$-lactams, sulphonamides, and tetracycline group antibiotics in animal husbandry to combat bacterial infections and stimulate growth [6]. The presence of these genes in mobile genetic elements, such as transposons and plasmids, can facilitate their transfer [33].

According to a study in the territory of the Russian Federation, the meat of productive animals contained aminoglycosides, phenicols, $\beta$-lactams, sulphonamides, and tetracycline group antibiotics in $36.7 \%, 23.2-30 \%, 13.3-16 \%, 23.2-29.6 \%$, and $18.5 \%$ of the studied samples, respectively [71].

The Salmonella strains SZL 30, SZL 31, and SZL 38 were potentially resistant to puromycin and erythromycin $(m d f A / c m r)$, as well as to novobiocin, nalidixic acid, and norfloxacin ( $m d t A B C$-tolC). Salmonella strains SZL 30 and SZL 31 were also resistant to rifampicin, erythromycin, and azithromycin (mefB) (Table 7). In the genomes of Salmonella strains SZL 30 and SZL 31, most antibiotic resistance genes were localized in plasmids.

The plasmid pSZL31.1 was $99.97 \%$ identical to pSZL30.1 at 96\% coverage. The main differences between pSZL30.1 and pSZL31.1 were the presence or absence of various mobile genetic elements and antibiotic resistance genes. Thus, plasmid pSZL30.1, unlike pSZL31.1, contained the IS2 and IS903B insertion elements. Unlike pSZL30.1, pSZL31.1 contained tet $A$ with a type I integron, which had at the $3^{\prime}$ terminus the gene cassette (sat1, $c m l A$, and $\left.q a c H\right)$ responsible for resistance to STR, chloramphenicol, and disinfectants (quaternary ammonium compound), which is coupled to the sul3-IS26 compound element for sulphonamide resistance (Figure 2A). The plasmids pSZL30.1 and pSZL31.1 contained type II integrons. The integron of pSZL30.1 bears the $a a d A 2 b$ gene for spectinomycin/streptomycin resistance, while the integron of pSZL31.1, apart from $a a d A 2 b$, also contains the $d f r A 14$ gene of trimethoprim resistance (Figure $2 \mathrm{~B}$ ).

At $98 \%$ coverage, the plasmid pSZL31.2 was 99.97\% identical to pSZL30.2. pSZL30.2 and pSZL31.2 contained the gene $b$ la $_{T E M-1 B}$, which had at the $3^{\prime}$ terminus a type I integron bearing the cassette of resistance genes coupled to the sul3-IS26 element of sulphonamide resistance. While in pSZL30.2 the resistance cassette contained the genes sat1, cmlA, aadA1, and $q a c H$, the cassette of pSZL31.2 contained the genes sat1, cmlA, and qacH (Figure 2A).

Comparison of the nucleotide sequences of the plasmids pSZL30.2 and pSZL31.2 with GenBank data revealed that they exhibited the highest homology (99.9\%) at 66\% coverage with an unnamed plasmid from Shigella flexneri strain 95-3008 (CP026773.1).

All antibiotic resistance genes detected in Salmonella strain SZL 38 were localized in the chromosome. Five genes, bla $a_{T E M-1 B}$, aph(6)-Id, aph(3")-Ib, sul2, and tet(B), were localized in a $17,949 \mathrm{nt}$ resistance island (Figure 2C). Comparison of the nucleotide sequences of this island with GenBank data revealed that it differed by one pointwise replacement from a similar island (CP019649.1) in the chromosome of S. enterica strain TW-Stm6 [72]. 


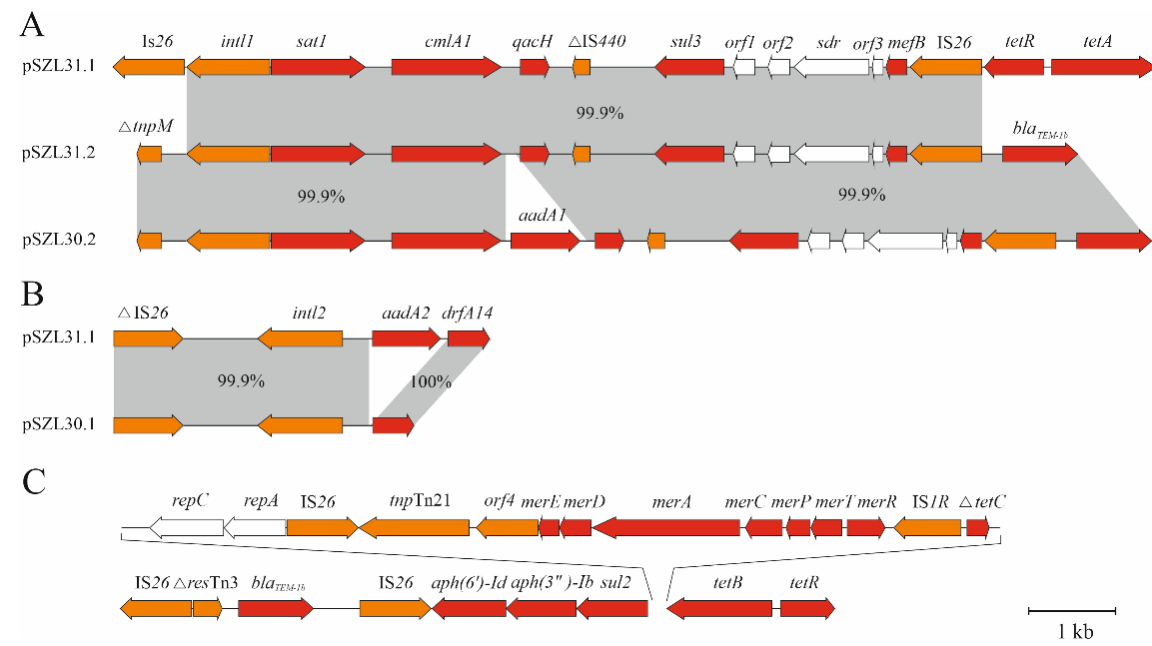

Figure 2. (A) Diagram of type I integrons and their flanking regions found in plasmids pSZL31.1, pSZL31.2, and pSZL30.2. (B) Schematic of type II integrons found in plasmids pSZL31.1 and pSZL30.1. (C) An island of resistance located on the chromosome of Salmonella S38. Red arrows indicate genes for resistance; orange genes are involved in the mobile transfer of genetic material. aadA1, aadA2b, $a p h\left(3^{\prime \prime}\right)-I b$, and $a p h(6)-I d$ - genes for streptomycin resistance, $b l a_{T E M-1 B}$-ampicillin resistance gene, cmlA1-chloramphenicol resistance gene, $d f r A 14$ - trimethoprim resistance gene, mefB-gene for resistance to macrolide antibiotics, qacH-gene for resistance to quaternary ammonium compounds, sul2 and sul3-genes for resistance to sulfamethoxazole, sat1-gene for resistance to streptothricin, tet $A$ and $t e t B$ - genes for resistance to tetracycline, tet $R$ - transcription regulator of genes tet $A$ and tet $B$. merRTPCADE-mercury resistance operon. intl1 and int12-integrases, IS26 and IS1R - insertion elements, orf1, orf2, orf3, and orf4—genes coding proteins with unknown function, sdr-short chain dehydrogenase, repA and repC-replication proteins, $\operatorname{tnp} \operatorname{Tn} 21$-transposase. $\Delta \mathrm{IS} 440, \Delta t e t C, \Delta t n p M$, and $\Delta$ resTn3-different variants of insertion element, transcription regulator, transposase, and resolvase, respectively.

AMR is a serious and growing problem for S. enterica and other Gram-negative pathogens [73]. Overuse of antibiotics in medicine and agriculture is the most important factor contributing to the emergence of bacteria resistant to various antibiotics [74]. Poultry, cattle, and pigs can act as effective carriers of Salmonella to humans [75-77].

AMR can occur as a result of point mutations in the bacterial genome or as a result of the horizontal transfer of genetic elements carrying resistance genes. Probably the most effective way of transferring antibiotic resistance genes between microorganisms is the horizontal transfer of mobile genetic elements-integrons, transposons, and plasmids containing one or more genes that determine antibiotic resistance [78,79]. In our work, it was shown that strains SZL 30 and SZL 31 contain plasmids pSZL30.1, pSZL30.2, pSZL31.1, and pSZL31.2, carrying various genes for antibiotic resistance (Figure 2). Integrons that are part of these plasmids and carry genes for antibiotic resistance are widespread in various strains of Salmonella, Proteus mirabilis, and E. coli. It is likely that these antibiotic resistance genes can be transmitted to other Gram-negative microorganisms, especially as a result of selective pressure caused by the use of antibiotics in agriculture.

\section{Materials and Methods}

\subsection{Strains Used in the Work}

In total, 32 Salmonella strains were included in the study. This study concerns 32 Salmonella strains isolated from 443 samples (112 samples from different types of poultry, 91 samples of pork, 103 samples of beef, and 168 samples of minced meat) collected in 2019 (Supplementary Table S4). 


\subsection{Isolation and Confirmation of Salmonella Isolates}

The preparation of samples, isolation, and identification of Salmonella was done according to techniques recommended by the International Organization for Standardization ISO 6579-1: 2017 [80]. Twenty-five grams from the skin of each sample was aseptically excised using a sterile scalpel then weighed and aseptically homogenized with $225 \mathrm{~mL}$ of sterile buffered peptone water (Oxoid, Basingstoke, UK) in a laboratory blender for $1 \mathrm{~min}$ and incubated at $37^{\circ} \mathrm{C}$ for $24 \mathrm{~h}$. One hundred microlitres from each pre-enrichment broth was inoculated into $10 \mathrm{~mL}$ of Rappaport-Vassiliadis broth (RV; Obolensk, Russian Federation) and incubated at $42{ }^{\circ} \mathrm{C}$ for $24 \mathrm{~h}$. Then, $1 \mathrm{~mL}$ from each pre-enrichment broth was inoculated into $10 \mathrm{~mL}$ of Muller-Kauffmann tetrathionate-novobiocin broth (MKTTn; Oxoid, Basingstoke, UK) and incubated at $37^{\circ} \mathrm{C}$ for $24 \mathrm{~h}$. A loopful of each enriched broth was streaked onto two selective solid media: xylose-lysine-desoxycholate (XLD) agar (Oxoid, Basingstoke, UK) and bismuth sulphite agar (Oxoid, Basingstoke, UK) then the inoculated plates were incubated at $37^{\circ} \mathrm{C}$ for $24 \mathrm{~h}$. All presumptive colonies on XLD and bismuth sulphite agar were picked up and cultured onto nutrient agar plates (FBUN SSC PMB, Obolensk, Russian Federation) and incubated at $37^{\circ} \mathrm{C}$ for $24 \mathrm{~h}$ to be subjected to further confirmation by biochemical and serological identifications. Specific colonies were confirmed by biochemical reactions using API 20E tests in accordance with the manufacturer's instructions (BioMérieux, Craponne, France) and frozen at $-86^{\circ} \mathrm{C}$ in collections of the Gorbatov Federal Centre of Food Systems. When the work started, strains were revitalized and characterized bacteriologically and biochemically to support their identities again.

\subsection{Serotyping of Salmonella Isolates}

Serotyping of Salmonella isolates was carried out by the molecular genetic method, using Check \& Trace Salmonella (Check-Points B.V., Wageningen, The Netherlands) according to the manufacturer's method (details available at http:/ / www.checkandtrace.com/, accessed on 21 July 2021).

\subsection{Screening of the Isolates for Resistance to Antimicrobial Preparations}

The sensitivity of Salmonella isolates to antimicrobial preparations was determined using the disk diffusion test on Muller-Hinton agar plates in accordance with the recommendations of the Clinical and Laboratory Standards Institute (CLSI) [81]. The following 12 antimicrobial preparations were tested: ampicillin (AMP) $10 \mu \mathrm{g}$, imipenem (IPM) $10 \mu \mathrm{g}$, amikacin (AMK) $10 \mu \mathrm{g}$, streptomycin (STR) $10 \mu \mathrm{g}$, tobramycin (TR) $10 \mu \mathrm{g}$, cefotaxime (CTX) $30 \mu \mathrm{g}$, cefazolin (CFZ) $30 \mu \mathrm{g}$, trimethoprim/sulfamethoxazole (SXT) 1.25/23.75 $\mu$ g, chloramphenicol $30 \mu \mathrm{g}$, azithromycin $15 \mu \mathrm{g}$, amoxicillin-clavulanic acid (AMC) 20/10 $\mu$, furadonin $300 \mu \mathrm{g}$, and tetracycline (TET) $30 \mu \mathrm{g}$. All antibiotic-containing paper disks were manufactured by the St. Petersburg Pasteur Institute, Russia. E. coli ATCC 25922 was used to control the quality of the research. The isolates were classified as sensitive, intermediate, or resistant according to CLSI [81]. The isolates resistant to three or more different classes of antimicrobial preparations were considered MDR.

\subsection{DNA Isolation and Sequencing}

LB medium $(5 \mathrm{~mL})$ was inoculated with the material from a single colony of Salmonella strain SZL 30, SZL 31, or SZL 38 and incubated for $16-20 \mathrm{~h}$ at $30{ }^{\circ} \mathrm{C}$ in a New Brunswick C-24 shaker incubator. The cells were separated on an Eppendorf MiniSpin centrifuge for $5 \mathrm{~min}$ at 10,000 rpm. Total DNA was isolated using a DNeasy PowerSoil Kit (Qiagen, Hilden, Germany) according to the manufacturer's recommendations.

The Salmonella spp. genomes were sequenced using Illumina technology (Illumina, San Diego, CA, USA) and monomolecular nanopore sequencing (Oxford Nanopore, Oxford, UK).

Genomic DNA (200 ng) was homogenized in a Bioruptor UCD 200 sonicator (Diagenode, Denville, NJ, USA) for $10 \mathrm{~min}$ at the maximal power (5 cycles of $30 \mathrm{~s}$ on $/ 90 \mathrm{~s}$ off). Paired DNA libraries $(300 \times 2)$ were obtained using a NEBNext ${ }^{\circledR}$ Ultra $^{\mathrm{TM}}$ II DNA Library 
Prep Kit (NEB) according to the manufacturer's conditions. The number and quality of the libraries thus obtained were determined using a Bioanalyzer 2100 capillary electrophoresis system (Agilent, Santa Clara, CA, USA). The DNA libraries were sequenced on MiSeq (Illumina) using a MiSeq Reagent Kit v3 (600-cycle; Illumina).

Genomic DNA was also sequenced using a MinION device (Oxford Nanopore, Oxford, UK). DNA libraries were obtained using a Ligation Sequencing Kit 1 D (SQK-LSK109) system (Oxford Nanopore), omitting the initial stage of genomic DNA fragmentation and then following the manufacturer's recommendations. Genomic libraries were sequenced on a MinION Flow Cell FLO-110.

\subsection{Bioinformatic Techniques}

The contigs from all Illumina and Nanopore reads were assembled using Unicycler v. 0.4 .8 [82].

In the next stage, pairwise intersecting reads obtained using MiSeq (Illumina) were combined using flash [83], and low-quality read ends were removed with Sickle. Complete genome sequences were assembled from the reads obtained on MiSeq and MinION using Flye 2.7 [84] and were twice corrected by Illumina reads with Pilon 1.22 [85].

Identification of genes and theoretical prediction of their functions were carried out using the RAST server [86,87].

The search for genes homologous to genes of antibiotic resistance was carried out using Comprehensive Antibiotic Resistance Database (CARD) [88] and ResFinder 4.1 (80\% identity and $60 \%$ gene coverage) [89]. The search for insertion sequences was carried out using the ISfinder server [90]. The plasmid type was determined using the Plasmid Finder 2.1 database [91]. The search for prophages was carried out using the Phage Search Tool Enhanced Release (PHASTER) server [92]. SPI presence and completeness were determined by comparison of the SPI nucleotide sequences [22,23] with the sequences of the genomes of Salmonella strains SZL 30, SZL 31, and SZL 38.

\subsection{Nucleotide Sequence Accession Number}

Whole genomes for Salmonella enterica were submitted in BioProject PRJNA774121, and BioSamples SAMN22551429, SAMN22551430, and SAMN22551506. The version described in this paper is the first version.

\section{Conclusions}

In conclusion, this study found a high incidence of MDR in various serotypes of Salmonella isolated from various types of food, including those commonly seen in infections in humans. Three strains with multiple AMRs (more than six) had different resistance genes with a heterogeneous distribution in the bacterial genome, which may indicate intense selection pressure during rearing and treatment of animals. Therefore, it is necessary to implement a plan to combat the abuse of antibiotics in veterinary medicine, as well as a system of epidemiological surveillance, including one based on whole-genome sequencing.

Supplementary Materials: The following are available online at https: / www.mdpi.com/article / 10.3390/antibiotics11010001/s1, Table S1: Sequencing statistics, Table S2: Pathogenicity Islands identified in the genomes of Salmonella strains, Table S3: Prophages identified in the genomes of Salmonella strains, Table S4: Bacterial strains used in the study.

Author Contributions: Conceptualization, Y.K.Y., A.V.M.; methodology, A.L.R., Y.K.Y., A.V.M.; software, A.L.R., A.V.B., T.E.T.; validation, E.V.Z., S.A.E. and S.O.S.; formal analysis, E.V.Z., A.V.M.; resources, Y.K.Y.; data curation, Y.K.Y., E.V.Z.; writing-original draft preparation, E.V.Z., T.V.K.; writing—review and editing, E.V.Z., A.V.M.; visualization, D.S.B.; supervision, Y.K.Y., A.A.S., O.A.K.: project administration, Y.K.Y.; funding acquisition, O.A.K. All authors have read and agreed to the published version of the manuscript.

Funding: This research was funded by the Ministry of Science and Higher Education of the Russian Federation, grant 075-15-2020-775. 
Institutional Review Board Statement: Not applicable.

Informed Consent Statement: Not applicable.

Data Availability Statement: Data is contained within the article and Supplementary Materials.

Conflicts of Interest: The authors declare no conflict of interest.

\section{References}

1. WHO. WHO Estimates of the Global Burden of Foodborne Diseases: Foodborne Disease Burden Epidemiology Reference Group 2007-2015; WHO: Geneva, Switzerland, 2015.

2. Lee, H.; Yoon, Y. Etiological Agents Implicated in Foodborne Illness World Wide. Food Sci. Anim. Resour. 2021, 41, 1-7. [CrossRef] [PubMed]

3. Zhao, S.; Li, C.; Hsu, C.-H.; Tyson, G.H.; Strain, E.; Tate, H.; Tran, T.-T.; Abbott, J.; McDermott, P.F. Comparative Genomic Analysis of 450 Strains of Salmonella enterica Isolated from Diseased Animals. Genes 2020, 11, 1025. [CrossRef]

4. State Report "About the State Sanitary and Epidemiological Welfare of the Population in Russian Federation in 2020". Available online: https://www.rospotrebnadzor.ru/upload/iblock/5fa/gd-seb_02.06-_s-podpisyu_.pdf (accessed on 28 October 2021).

5. Nesbitt, A.; Ravel, A.; Murray, R.; McCORMICK, R.; Savelli, C.; Finley, R.; Parmley, J.; Agunos, A.; Majowicz, S.E.; Gilmour, M.; et al. Integrated surveillance and potential sources of Salmonella enteritidis in human cases in Canada from 2003 to 2009. Epidemiol. Infect. 2012, 140, 1757-1772. [CrossRef] [PubMed]

6. Layton, A.N.; Galyov, E.E. Salmonella-induced enteritis: Molecular pathogenesis and therapeutic implications. Expert Rev. Mol. Med. 2007, 9, 1-17. [CrossRef] [PubMed]

7. Angulo, F.J.; Johnson, K.R.; Tauxe, R.V.; Cohen, M.L. Origins and Consequences of Antimicrobial-Resistant Nontyphoidal Salmonella: Implications for the Use of Fluoroquinolones in Food Animals. Microb. Drug Resist. 2000, 1, 77. [CrossRef] [PubMed]

8. Parry, C.M.; Threlfall, E.J. Antimicrobial resistance in typhoidal and nontyphoidal salmonellae. Curr. Opin. Infect. Dis. 2008, 5 , 531-538. [CrossRef] [PubMed]

9. Patchanee, P.; Tansiricharoenkul, K.; Buawiratlert, T.; Wiratsudakul, A.; Angchokchatchawal, K.; Yamsakul, P.; Yano, T.; Boonkhot, P.; Rojanasatien, S.; Tadee, P. Salmonella in pork retail outlets and dissemination of its pulsotypes through pig production chain in Chiang Mai and surrounding areas, Thailand. Prev. Veter. Med. 2016, 130, 99-105. [CrossRef]

10. Possebon, F.S.; Casas, R.; Nero, A.; Yamatogi, S.; Araújo, P.; Pinto, P. Prevalence, antibiotic resistance, PFGE and MLST characterization of Salmonella in swine mesenteric lymph nodes. Prev. Veter. Med. 2020, 179, 105024. [CrossRef]

11. Thai, T.H.; Hirai, T.; Lan, N.T.; Yamaguchi, R. Antibiotic resistance profiles of Salmonella serovars isolated from retail pork and chicken meat in North Vietnam. Int. J. Food Microbiol. 2012, 2, 147-151. [CrossRef] [PubMed]

12. Phillips, A.; Sotomayor, C.; Wang, Q.; Holmes, N.; Furlong, C.; Ward, K.; Howard, P.; Octavia, S.; Lan, R.; Sintchenko, V. Whole genome sequencing of Salmonella typhimurium illuminates distinct outbreaks caused by an endemic multi-locus variable number tandem repeat analysis type in Australia, 2014. BMC Microbiol. 2016, 16, 1-9. [CrossRef]

13. Cummins, M.L.; Sanderson-Smith, M.; Newton, P.; Carlile, N.; Phalen, D.N.; Maute, K.; Monahan, L.G.; Hoye, B.J.; Djordjevic, S.P. Whole-Genome Sequence Analysis of an Extensively Drug-Resistant Salmonella enterica Serovar Agona Isolate from an Australian Silver Gull (Chroicocephalus novaehollandiae) Reveals the Acquisition of Multidrug Resistance Plasmids. $m S p h e r e$ 2020, 5, 5. [CrossRef]

14. Cohen, E.; Rahav, G.; Gal-Mor, O. Genome Sequence of an Emerging Salmonella enterica Serovar Infantis and Genomic Comparison with Other S. Infantis Strains. Genome Biol. Evol. 2020, 3, 151-159. [CrossRef]

15. Mashe, T.; Leekitcharoenphon, P.; Mtapuri-Zinyowera, S.; A Kingsley, R.; Robertson, V.; Tarupiwa, A.; Kock, M.M.; Makombe, E.P.; Chaibva, B.V.; Manangazira, P.; et al. Salmonella enterica serovar Typhi H58 clone has been endemic in Zimbabwe from 2012 to 2019. J. Antimicrob. Chemother. 2021, 5, 1160-1167. [CrossRef]

16. Wahl, A.; Battesti, A.; Ansaldi, M. Prophages in Salmonella enterica: A driving force in reshaping the genome and physiology of their bacterial host? Mol. Microbiol. 2019, 2, 303-316. [CrossRef] [PubMed]

17. Munita, J.M.; Arias, C.A. Mechanisms of Antibiotic Resistance. Microbiol. Spectr. 2016, 2, 1-37.

18. Wencewicz, T.A. Crossroads of Antibiotic Resistance and Biosynthesis. J. Mol. Biol. 2019, 431, 3370-3399. [CrossRef] [PubMed]

19. Castro-Vargas, R.E.; Herrera-Sánchez, M.P.; Rodríguez-Hernández, R.; Rondón-Barragán, I.S. Antibiotic resistance in Salmonella spp. isolated from poultry: A global overview. Vet. World 2020, 10, 2070-2084. [CrossRef]

20. He, D.; Zhu, Y.; Li, R.; Pan, Y.; Liu, J.; Yuan, L.; Hu, G. Emergence of a hybrid plasmid derived from IncN1-F33:A-:B- and mcr-1-bearing plasmids mediated by IS26. J. Antimicrob. Chemother. 2019, 11, 3184-3189. [CrossRef] [PubMed]

21. Hsu, C.-H.; Li, C.; Hoffmann, M.; McDermott, P.; Abbott, J.; Ayers, S.; Tyson, G.H.; Tate, H.; Yao, K.; Allard, M.; et al. Comparative Genomic Analysis of Virulence, Antimicrobial Resistance, and Plasmid Profiles of Salmonella Dublin Isolated from Sick Cattle, Retail Beef, and Humans in the United States. Microb. Drug Resist. 2019, 8, 1238-1249. [CrossRef] [PubMed]

22. Mansour, M.N.; Yaghi, J.; El Khoury, A.; Felten, A.; Mistou, M.-Y.; Atoui, A.; Radomski, N. Prediction of Salmonella serovars isolated from clinical and food matrices in Lebanon and genomic-based investigation focusing on Enteritidis serovar. Int. J. Food Microbiol. 2020, 333, 108831. [CrossRef] [PubMed] 
23. Hayward, M.R.; Jansen, V.A.; Woodward, M.J. Comparative genomics of Salmonella enterica serovars Derby and Mbandaka, two prevalent serovars associated with different livestock species in the UK. BMC Genom. 2013, 14, 365. [CrossRef]

24. Antunes, P.; Mourão, J.; Campos, J.; Peixe, L. Salmonellosis: The role of poultry meat. Clin. Microbiol. Infect. 2016, 22, 110-121. [CrossRef] [PubMed]

25. Mechesso, A.F.; Moon, D.C.; Kim, S.-J.; Song, H.-J.; Kang, H.Y.; Na, S.H.; Choi, J.-H.; Kim, H.-Y.; Yoon, S.-S.; Lim, S.-K. Nationwide surveillance on serotype distribution and antimicrobial resistance profiles of non-typhoidal Salmonella serovars isolated from food-producing animals in South Korea. Int. J. Food Microbiol. 2020, 335, 108893. [CrossRef] [PubMed]

26. Hendriksen, R.S.; Vieira, A.R.; Karlsmose, S.; Lo Fo Wong, D.M.; Jensen, A.B.; Wegener, H.C.; Aarestrup, F.M. Global Monitoring of Salmonella Serovar Distribution from the World Health Organization Global Foodborne Infections Network Country Data Bank: Results of Quality Assured Laboratories from 2001 to 2007. Foodborne Pathog. Dis. 2011, 8, 887-900. [CrossRef] [PubMed]

27. Issenhuth-Jeanjean, S.; Roggentin, P.; Mikoleit, M.; Guibourdenche, M.; de Pinna, E.; Nair, S.; Fields, P.I.; Weill, F.-X. Supplement 2008-2010 (no. 48) to the White-Kauffmann-Le Minor scheme. Res. Microbiol. 2014, 165, 526-530. [CrossRef]

28. Kürekci, C.; Sahin, S.; Iwan, E.; Kwit, R.; Bomba, A.; Wasyl, D. Whole-genome sequence analysis of Salmonella infantis isolated from raw chicken meat samples and insights into pESI-like megaplasmid. Int. J. Food Microbiol. 2021, 337, 108956. [CrossRef]

29. Yang, X.; Wu, Q.; Zhang, J.; Huang, J.; Chen, L.; Wu, S.; Zeng, H.; Wang, J.; Chen, M.; Wu, H.; et al. Prevalence, Bacterial Load, and Antimicrobial Resistance of Salmonella Serovars Isolated From Retail Meat and Meat Products in China. Front. Microbiol. 2019, 10, 2121. [CrossRef] [PubMed]

30. Yang, X.; Wu, Q.; Zhang, J.; Huang, J.; Chen, L.; Liu, S.; Yu, S.; Cai, S. Prevalence, enumeration, and characterization of Salmonella isolated from aquatic food products from retail markets in China. Food Control 2015, 57, 308-313. [CrossRef]

31. Sadkowska-Todys, M.; Czarkowski, M.P. Salmonellosis in Poland in 2012. Przeglad Epidemiol. 2014, 68, $243-248$.

32. Fernandes, S.A.; Tavechio, A.T.; Ghilardi, Â.C.; Dias, Â.M.; De Almeida, I.A.; De Melo, L.C. Salmonella serovars isolated from humans in São Paulo State, Brazil, 1996-2003. Rev. Do Inst. De Med. Trop. De São Paulo 2006, 48, 179-184. [CrossRef] [PubMed]

33. Lee, W.; Puthucheary, S.; Boey, C. Non-typhoid Salmonella gastroenteritis. J. Paediatr. Child Health 1998, 34, 387-390. [CrossRef] [PubMed]

34. Spiliopoulou, I.; Zografou, S.; Goula, A.; Dimitracopoulos, G.; Christofidou, M. Molecular Epidemiology and Antibiotic Resistance Patterns of Salmonella enterica from Southwestern Greece. Chemotherapy 2007, 53, 392-396. [CrossRef]

35. Li, Y.; Xie, X.; Xu, X.; Wang, X.; Chang, H.; Wang, C.; Wang, A.; He, Y.; Yu, H.; Wang, X.; et al. Nontyphoidal Salmonella Infection in Children with Acute Gastroenteritis: Prevalence, Serotypes, and Antimicrobial Resistance in Shanghai, China. Foodborne Pathog. Dis. 2014, 11, 200-206. [CrossRef] [PubMed]

36. Wotzka, S.Y.; Nguyen, B.D.; Hardt, W.-D. Salmonella Typhimurium Diarrhea Reveals Basic Principles of Enteropathogen Infection and Disease-Promoted DNA Exchange. Cell Host Microbe 2017, 21, 443-454. [CrossRef] [PubMed]

37. Martínez-Chávez, L.; Cabrera-Diaz, E.; Pérez-Montaño, J.; Garay-Martínez, L.; Varela-Hernández, J.; Castillo, A.; Lucia, L.; ÁvilaNovoa, M.; Cardona-Lopez, M.A.; Gutiérrez-González, P.; et al. Quantitative distribution of Salmonella spp. and Escherichia coli on beef carcasses and raw beef at retail establishments. Int. J. Food Microbiol. 2015, 210, 149-155. [CrossRef] [PubMed]

38. Molina-López, R.A.; Vidal, A.; Obón, E.; Martín, M.; Darwich, L. Multidrug-resistant Salmonella enterica Serovar Typhimurium Monophasic Variant 4,12:i:- Isolated from Asymptomatic Wildlife in a Catalonian Wildlife Rehabilitation Center, Spain. J. Wildl. Dis. 2015, 3, 759-763. [CrossRef] [PubMed]

39. Arnedo-Pena, A.; Sabater-Vidal, S.; Herrera-León, S.; Bellido-Blasco, J.B.; Silvestre-Silvestre, E.; Meseguer-Ferrer, N.; YagueMuñoz, A.; Gil-Fortuño, M.; Romeu-García, A.; Moreno-Muñoz, R. An outbreak of monophasic and biphasic Salmonella typhimurium, and Salmonella derby associated with the consumption of dried pork sausage in Castellon (Spain). Enferm. Infecc. Y Microbiol. Clínica 2016, 9, 544-550. [CrossRef] [PubMed]

40. Xu, Z.; Wang, M.; Zhou, C.; Gu, G.; Liang, J.; Hou, X.; Wang, M.; Wei, P. Prevalence and antimicrobial resistance of retail-meatborne Salmonella in southern China during the years 2009-2016: The diversity of contamination and the resistance evolution of multidrug-resistant isolates. Int. J. Food Microbiol. 2020, 333, 108790. [CrossRef] [PubMed]

41. Yin, X.; M'Ikanatha, N.M.; Nyirabahizi, E.; McDermott, P.F.; Tate, H. Antimicrobial resistance in non-Typhoidal Salmonella from retail poultry meat by antibiotic usage-related production claims-United States, 2008-2017. Int. J. Food Microbiol. 2021, $342,10904$. [CrossRef]

42. Hu, L.; Cao, G.; Brown, E.W.; Allard, M.W.; Ma, L.M.; Khan, A.A.; Zhang, G. Antimicrobial resistance and related gene analysis of Salmonella from egg and chicken sources by whole-genome sequencing. Poult. Sci. 2020, 99, 7076-7083. [CrossRef] [PubMed]

43. Cai, Y.; Tao, J.; Jiao, Y.; Fei, X.; Zhou, L.; Wang, Y.; Zheng, H.; Pan, Z.; Jiao, X. Phenotypic characteristics and genotypic correlation between Salmonella isolates from a slaughterhouse and retail markets in Yangzhou, China. Int. J. Food Microbiol. 2016, $222,56-64$. [CrossRef] [PubMed]

44. Chen, S.; Zhao, S.; White, D.G.; Schroeder, C.M.; Lu, R.; Yang, H.; McDermott, P.F.; Ayers, S.; Meng, J. Characterization of Multiple-Antimicrobial-Resistant Salmonella Serovars Isolated from Retail Meats. Appl. Environ. Microbiol. 2004, 70, 1-7. [CrossRef] [PubMed]

45. Yang, B.; Qu, D.; Zhang, X.; Shen, J.; Cui, S.; Shi, Y.; Xi, M.; Sheng, M.; Zhi, S.; Meng, J. Prevalence and characterization of Salmonella serovars in retail meats of marketplace in Shaanxi, China. Int. J. Food Microbiol. 2010, 141, 63-72. [CrossRef] [PubMed]

46. Barbosa, T.M.; Levy, S.B. The impact of antibiotic use on resistance development and persistence. Drug Resist. Updat. 2000, 3, 303-311. [CrossRef] [PubMed] 
47. Cui, M.; Xie, M.; Qu, Z.; Zhao, S.; Wang, J.; Wang, Y.; He, T.; Wang, H.; Zuo, Z.; Wu, C. Prevalence and antimicrobial resistance of Salmonella isolated from an integrated broiler chicken supply chain in Qingdao, China. Food Control 2016, 62, 270-276. [CrossRef]

48. Bada-Alambedji, R.; Fofana, A.; Seydi, M.; Akakpo, A.J. Antimicrobial resistance of Salmonella isolated from poultry carcasses in Dakar (Senegal). Braz. J. Microbiol. 2006, 4, 510-515. [CrossRef]

49. Tibaijuka, B.; Molla, B.; Hildebrandt, G.; Kleer, J.; Salah, W. Antimicrobila resistance to Salmonellae isolated from retail raw chicken meat and giblets in Ethiopia. Bull. Anim. Health Prod. Afr. 2002, 2, 86-95. [CrossRef]

50. Elkenany, R.; Elsayed, M.M.; Zakaria, A.I.; El-Sayed, S.A.-E.-S.; Rizk, M.A. Antimicrobial resistance profiles and virulence genotyping of Salmonella enterica serovars recovered from broiler chickens and chicken carcasses in Egypt. BMC Veter. Res. 2019, 1, 124. [CrossRef] [PubMed]

51. Vélez, D.C.; Rodríguez, V.; García, N.V. Phenotypic and Genotypic Antibiotic Resistance of Salmonella from Chicken Carcasses Marketed at Ibague, Colombia. Rev. Bras. De Ciência Avícola 2017, 2, 347-354. [CrossRef]

52. Shrestha, P.; Cooper, B.S.; Coast, J.; Oppong, R.; Thuy, N.D.T.; Phodha, T.; Celhay, O.; Guerin, P.J.; Wertheim, H.; Lubell, Y Enumerating the economic cost of antimicrobial resistance per antibiotic consumed to inform the evaluation of interventions affecting their use. Antimicrob. Resist. Infect. Control. 2018, 7, 1-9. [CrossRef] [PubMed]

53. Shaw, K.J.; Rather, P.N.; Hare, R.S.; Miller, G.H. Molecular genetics of aminoglycoside resistance genes and familial relationships of the aminoglycoside-modifying enzymes. Microbiol. Rev. 1993, 1, 98. [CrossRef] [PubMed]

54. Kor, S.-B.; Choo, Q.-C.; Chew, C.-H. New integron gene arrays from multiresistant clinical isolates of members of the Enterobacteriaceae and Pseudomonas aeruginosa from hospitals in Malaysia. J. Med. Microbiol. 2013, 3, 412-420. [CrossRef] [PubMed]

55. Kazama, H.; Kizu, K.; Iwasaki, M.; Hamashima, H.; Sasatsu, M.; Arai, T. Isolation and structure of a new integron that includes a streptomycin resistance gene from the R plasmid of Pseudomonas aeruginosa. FEMS Microbiol. Lett. 1995, 134, 137-141. [CrossRef]

56. Sundin, G.W. Distinct Recent Lineages of the strA-strB Streptomycin-Resistance Genes in Clinical and Environmental Bacteria Curr. Microbiol. 2002, 1, 63-69. [CrossRef]

57. Scholz, P.; Haring, V.; Wittmann-Liebold, B.; Ashman, K.; Bagdasarian, M.; Scherzinger, E. Complete nucleotide sequence and gene organization of the broad-host-range plasmid RSF1010. Gene 1989, 2, 271-288. [CrossRef]

58. Villa, L.; García-Fernández, A.; Fortini, D.; Carattoli, A. Replicon sequence typing of IncF plasmids carrying virulence and resistance determinants. J. Antimicrob. Chemother. 2010, 65, 2518-2529. [CrossRef] [PubMed]

59. Alcaine, S.; Warnick, L.D.; Wiedmann, M. Antimicrobial Resistance in Nontyphoidal Salmonella. J. Food Prot. 2007, 70, 3. [CrossRef]

60. Greenwood, D.; Finch, R.; Davey, P.; Wilcox, M. Antimicrobial Chemotherapy; Oxford University Press: Oxford, UK, 2007.

61. Stürenburg, E.; Mack, D. Extended-spectrum $\beta$-lactamases: Implications for the clinical microbiology laboratory, therapy, and infection control. J. Infect. 2003, 47, 273-295. [CrossRef]

62. McClelland, M.; Sanderson, K.E.; Spieth, J.; Clifton, S.W.; Latreille, P.; Courtney, L.; Porwollik, S.; Ali, J.; Dante, M.; Du, F.; et al. Complete genome sequence of Salmonella enterica serovar Typhimurium LT2. Nature 2001, 413, 852-856. [CrossRef]

63. Salipante, S.J. Determining the Limits of the Evolutionary Potential of an Antibiotic Resistance Gene. Mol. Biol. Evol. 2003, 4 , 653-659. [CrossRef] [PubMed]

64. Perreten, V.; Boerlin, P. A New Sulfonamide Resistance Gene (sul3) in Escherichia coli Is Widespread in the Pig Population of Switzerland. Antimicrob. Agents Chemother. 2003, 47, 1169-1172. [CrossRef]

65. Cain, A.; Hall, R.M. Evolution of a multiple antibiotic resistance region in IncHI1 plasmids: Reshaping resistance regions in situ. J. Antimicrob. Chemother. 2012, 12, 2848-2853. [CrossRef] [PubMed]

66. Ojo, K.K.; Kehrenberg, C.; Schwarz, S.; Odelola, H.A. Identification of a Complete dfrA14 Gene Cassette Integrated at a Secondary Site in a Resistance Plasmid of Uropathogenic Escherichia coli from Nigeria. Antimicrob. Agents Chemother. 2002, 6, 2054-2055. [CrossRef] [PubMed]

67. Sørum, H.; L'Abée-Lund, T.M.; Solberg, A.; Wold, A. Integron-Containing IncU R Plasmids pRAS1 and pAr-32 from the Fish Pathogen Aeromonas salmonicida. Antimicrob. Agents Chemother. 2003, 4, 1285-1290. [CrossRef]

68. Lau, S.K.P.; Wong, G.K.M.; Li, M.W.S.; Woo, P.C.Y.; Yuen, K.-Y. Distribution and molecular characterization of tetracycline resistance in Laribacter hongkongensis. J. Antimicrob. Chemother. 2008, 61, 488-497. [CrossRef]

69. Yamaguchi, A.; Adachi, K.; Akasaka, T.; Ono, N.; Sawai, T. Metal-tetracycline/H+ antiporter of Escherichia coli encoded by a transposon, Tn10. The role of the conserved dipeptide, Ser65-Asp66, in tetracycline transport. J. Biol. Chem. 1990, 265, 15525-15530. [CrossRef]

70. Bissonnette, L.; Champetier, S.; Buisson, J.P.; Roy, P.H. Characterization of the nonenzymatic chloramphenicol resistance (cmlA) gene of the In4 integron of Tn1696: Similarity of the product to transmembrane transport proteins. J. Bacteriol. 1991, 14, 4493-4502. [CrossRef] [PubMed]

71. Zayko, E.V.; Kuznetsova, O.A.; Bataeva, D.S.; Grudistova, M.A. Identification of antibiotics in meat. Flow cytometry capabilities. All Meat 2020, 5, 56-60. [CrossRef]

72. Dyall-Smith, M.L.; Liu, Y.; Billman-Jacobe, H. Genome Sequence of an Australian Monophasic Salmonella enterica subsp. enterica Typhimurium Isolate (TW-Stm6) Carrying a Large Plasmid with Multiple Antimicrobial Resistance Genes. Genome Announc. 2017, 5, e00793-17. [CrossRef] 
73. O'Mahony, R.; Quinn, T.; Drudy, D.; Walsh, C.; Whyte, P.; Mattar, S.; Fanning, S. Antimicrobial Resistance in Nontyphoidal Salmonella from Food Sources in Colombia: Evidence for an Unusual Plasmid-Localized Class 1 Integron in Serotypes Typhimurium and Anatum. Microb. Drug Resist. 2006, 12, 269-277. [CrossRef] [PubMed]

74. NARMS Integrated Report: 2014. Available online: https://www.fda.gov/media/101511/download (accessed on 2 December 2021).

75. Li, B.; Yang, X.; Tan, H.; Ke, B.; He, D.; Wang, H.; Chen, Q.; Ke, C.; Zhang, Y. Whole genome sequencing analysis of Salmonella enterica serovar Weltevreden isolated from human stool and contaminated food samples collected from the Southern coastal area of China. Int. J. Food Microbiol. 2018, 266, 317-323. [CrossRef] [PubMed]

76. Wray, C.; Davies, R.H. Salmonella in Domestic Animals, 2nd ed.; CABI Publishing: Wallingford, UK, $2000 ;$ pp. 169-190.

77. Barilli, E.; Bacci, C.; Villa, Z.S.; Merialdi, G.; D’Incau, M.; Brindani, F.; Vismarra, A. Antimicrobial resistance, biofilm synthesis and virulence genes in Salmonella isolated from pigs bred on intensive farms. Ital. J. Food Saf. 2018, 7, 7223. [CrossRef] [PubMed]

78. Carattoli, A. Importance of integrons in the diffusion of resistance. Veter. Res. 2001, 32, 243-259. [CrossRef]

79. Carattoli, A.; Villa, L.; Pezzella, C.; Bordi, E.; Visca, P. Expanding Drug Resistance through Integron Acquisition by IncFI Plasmids of Salmonella enterica Typhimurium. Emerg. Infect. Dis. 2001, 7, 444. [CrossRef] [PubMed]

80. Anonymous. Microbiology of the Food Chain-Horizontal Method for the Detection, Enumeration and Serotyping of Salmonella-Part 1: Detection of Salmonella spp; ISO 6579-1; International Organization for Standardization: Geneva, Switzerland, 2017.

81. CLSI. Performance Standards for Antimicrobial Disk Susceptibility Tests, M100S, 29th ed.; CLSI: Wayne, PA, USA, 2019 ; Volume 39.

82. Wick, R.R.; Judd, L.M.; Gorrie, C.L.; Holt, K.E. Unicycler: Resolving bacterial genome assemblies from short and long sequencing reads. PLoS Comput. Biol. 2017, 6, e1005595. [CrossRef] [PubMed]

83. Magoč, T.; Salzberg, S.L. FLASH: Fast length adjustment of short reads to improve genome assemblies. Bioinformatics 2011, 27, 2957-2963. [CrossRef]

84. Kolmogorov, M.; Yuan, J.; Lin, Y.; Pevzner, P.A. Assembly of long, error-prone reads using repeat graphs. Nat. Biotechnol. 2019, 37, 540-546. [CrossRef]

85. Walker, B.J.; Abeel, T.; Shea, T.; Priest, M.; Abouelliel, A.; Sakthikumar, S.; Cuomo, C.A.; Zeng, Q.; Wortman, J.; Young, S.K.; et al. Pilon: An Integrated Tool for Comprehensive Microbial Variant Detection and Genome Assembly Improvement. PLoS ONE 2014, 11, e112963. [CrossRef]

86. Aziz, R.K.; Bartels, D.; Best, A.A.; DeJongh, M.; Disz, T.; Edwards, R.A.; Formsma, K.; Gerdes, S.; Glass, E.M.; Kubal, M.; et al. The RAST Server: Rapid Annotations using Subsystems Technology. BMC Genom. 2008, 9, 75. [CrossRef]

87. Overbeek, R.; Olson, R.; Pusch, G.D.; Olsen, G.J.; Davis, J.J.; Disz, T.; Edwards, R.A.; Gerdes, S.; Parrello, B.; Shukla, M.; et al The SEED and the Rapid Annotation of microbial genomes using Subsystems Technology (RAST). Nucleic Acids Res. 2014, 42, D206-D214. [CrossRef]

88. McArthur, A.G.; Waglechner, N.; Nizam, F.; Yan, A.; Azad, M.A.; Baylay, A.J.; Bhullar, K.; Canova, M.J.; De Pascale, G.; Ejim, L.; et al. The Comprehensive Antibiotic Resistance Database. Antimicrob. Agents Chemother. 2013, 57, 3348-3357. [CrossRef] [PubMed]

89. Bortolaia, V.; Kaas, R.S.; Ruppe, E.; Roberts, M.C.; Schwarz, S.; Cattoir, V.; Philippon, A.; Allesoe, R.L.; Rebelo, A.R.; Florensa, A.F.; et al. ResFinder 4.0 for predictions of phenotypes from genotypes. J. Antimicrob. Chemother. 2020, 12, 3491-3500. [CrossRef] [PubMed]

90. Siguier, P.; Perochon, J.; Lestrade, L.; Mahillon, J.; Chandler, M. ISfinder: The reference centre for bacterial insertion sequences. Nucleic Acids Res. 2006, 34, D32-D36. [CrossRef] [PubMed]

91. Carattoli, A.; Zankari, E.; García-Fernández, A.; Larsen, M.V.; Lund, O.; Villa, L.; Aarestrup, F.M.; Hasman, H. In Silico Detection and Typing of Plasmids using PlasmidFinder and Plasmid Multilocus Sequence Typing. Antimicrob. Agents Chemother. 2014, 7, 3895-3903. [CrossRef]

92. Arndt, D.; Grant, J.R.; Marcu, A.; Sajed, T.; Pon, A.; Liang, Y.; Wishart, D.S. PHASTER: A better, faster version of the PHAST phage search tool. Nucleic Acids Res. 2016, 44, 16-21. [CrossRef] 